\title{
Study on the Key Technology of Electrochemical Machining Flow Field in Aero-Rotor Blades
}

\author{
Liang Huang \\ Xi'an Technological University \\ Yan Cao ( $\nabla$ caoyan@xatu.edu.cn ) \\ Xi'an Technological University \\ Chunlei Tian \\ Xi'an Technological University \\ Ruochen Zhao \\ Xi'an Technological University \\ Jiang Du \\ Xi'an Technological University \\ Yuanfei Wang \\ Xi'an KunLun Industry (Group) Company with Limited Liability
}

\section{Research Article}

Keywords: Aero-rotor blades, Electrochemical machining, Viscous fluid, Flow field, Finite element numerical simulation

Posted Date: February 25th, 2021

DOl: https://doi.org/10.21203/rs.3.rs-239624/v1

License: (c) (i) This work is licensed under a Creative Commons Attribution 4.0 International License.

Read Full License 


\title{
Study on the key technology of electrochemical machining flow field in aero-rotor blades
}

\author{
Liang Huang ${ }^{\mathrm{a}}$, Yan Cao ${ }^{\mathrm{a}, *}$, Chunlei Tian ${ }^{\mathrm{a}}$, Ruochen Zhao ${ }^{\mathrm{b}}$, Jiang Du ${ }^{\mathrm{a}}$, Yuanfei Wang ${ }^{\mathrm{c}}$ \\ ${ }^{a}$ Mechatronic Engineering, Xi'an Technological University, Xi'an 710021, China \\ ${ }^{\mathrm{b}}$ Ministry of Science and Technology, Xi'an Technological University, Xi'an 710021, China \\ 'Tool Structure Manufacturing, Xi'an KunLun Industry (Group) Company with Limited Liability, Xi'an 710021, China \\ * Yan Cao. Tel.: 029-86173054; fax: +0-000-000-0000. E-mail address: caoyan@ xatu.edu.cn
}

\begin{abstract}
With the rapid development of aerospace industry in recent years, the use of aero-rotor engine blades with new special alloy materials and high distortion and thin-walled structure has been paid more and more attention. Aiming at the problems of poor tool accessibility, serious tool loss and easy deformation of blade profile in NC milling technology, electrochemical machining can realize the processing of complex special structure products with advanced materials by means of non-contact electrochemical etching process. However, in the process of electrochemical etching, the flow channel structure of electrochemical machining affects the stability of the distribution of electrochemical etching characteristics in various parts of the machining surface and ultimately acts on the forming quality by controlling the liquid phase mass transfer process in the machining gap. Therefore, reasonable design and optimization of the flow channel is of great significance in the process of electrochemical machining. In this paper, based on the existing traditional vertical single-axis feed machining mode and combined with the traditional side flow processing blade flow characteristics, innovatively proposed two kinds of electrolyte flow schemes under the vertical machining mode; Then, based on the above two flow channel structures and the energy loss characteristics of viscous fluid during liquid phase mass transfer, a mathematical model of liquid phase mass transfer flow field is established, which combines the viscosity loss characteristics of electrolyte, and by introducing a optimized flow channel structure that combined with the characteristics of positive flow and side flow and adjusting the parameters of electrolyte inlet / outlet, the optimal design channel structure and uniform flow field of aero-rotor blades are realized. Finally, the accuracy and rationality of the proposed scheme are verified by electrochemical machining verification test, which lays a research foundation and guarantee for the feasibility and accuracy of vertical electrochemical machining machine tool in aero-rotor blades.

Keywords Aero-rotor blades Electrochemical machining Viscous fluid Flow field Finite element numerical simulation
\end{abstract}

\section{Introduction}

As the core component of aero-engine, the quality of rotor blade directly determines the performance [1] of aero-engine. Along with the rapid development of aerospace industry in recent years, the light weight and high performance of the material under the action of gas working fluid through high distortion and thin-walled blade structure has gradually become the development goal of the new generation aeroengine [2-3], and the complex shaped structure products with this new special alloy material have the poor tool accessibility, serious tool loss and easy deformation of blade profile in NC milling technology [4]; and the thermal re-casting layer and the heat affected zone after EDM will interfere with the forming quality of the key parts of the blade surface [5]. While electrochemical machining (ECM), as a non-contact electrochemical etching technology, can solve the problems of traditional NC milling by virtue of its advantages of not limited by the properties of workpiece materials, no loss of tool cathode and high machining efficiency [6], and electrochemical machining uses high-speed electrolyte to replace EDM with high-temperature breakdown discharge melting by electrochemical etching, thus avoiding the influence of hot casting layer and heat affected zone on molding quality to obtain excellent surface [7]. However, for electrochemical machining, electrochemical etching of anode materials is completely based on the electrochemical characteristic distribution of the electrolyte in the machining gap, considering that the distribution of electrolyte electrochemical characteristics in the machining gap is determined by the electrolyte flow channel structure by controlling the fluid mass transfer process, and finally acting on the forming quality through the distribution of electrochemical etching characteristics in various parts of the machining surface, therefore, the rational design and optimization of the flow channel is of great significance in the process of ECM.

In view of the design and analysis of the flow field of the aero-rotor blade of electrochemical machining, it has been a hot topic in the field of electrochemical machining in recent years. At present, some scholars have carried out a series of studies on this part, such as: in terms of flow field structure design, Zhu D [8] proposed a new dynamic lateral flow mode of electrolyte, in which the electrolyte flows from the leading 
edge to the trailing edge, was proposed in trepanning ECM of a diffuser, and this flow field can achieve the precision machining of surface up to $0.12 \mathrm{~mm}$ under the condition of uniform flow field distribution in electrode gap; Xu ZY [9] proposed a two-way flow mode of electrolyte under the single edge plate blade, that is, the electrolyte flows from both sides of the edge plate and flows through the blade basin and the blade back channel respectively, and the numerical simulation method and the verification experiment method are compared with the traditional side flow mode to verify the improvement of the uniformity and stability of the flow field by using the active control flow mode; Subsequently, Liu J et al [10] of Nanjing University of Aeronautics and Astronautics proposed a three-dimensional composite electrolyte flow pattern for the whole blade disk; Based on this, Sawicki J [11] optimized the flow field uniformity distribution by adjusting the machining gap and flow velocity in the process of side flow machining on blade surface. In terms of numerical simulation of flow field: by associating fluid flow, fluid heat transfer and energy conservation, Chen YL [12] established an interdisciplinary simulation model for the electrochemical machining process of aero-engine blades, and verified the rationality and accuracy of the proposed simulation model by optical in situ measurement; The effect of flow field parameters on machining clearance was analyzed by correlating the turbulence model of k-epsilon flow channel with Euler dual model considering viscous resistance and pressure force, and the prediction results of machining clearance are consistent with the experimental results (the maximum deviation is less than $50 \mu \mathrm{m})$.

Through the analysis of the above literature, the design and simulation of the flow field for the aero rotor blades are mainly focused on the optimization and improvement of the traditional electrolyte side flow processing technology. And the application of most design results still needs to be guaranteed by the design of side flow electrolytic machining machine tools, which will lead to a large increase in research costs and a decrease in research efficiency. Therefore, this paper based on the existing traditional vertical single-axis feed machining mode and combined with the traditional side flow processing blade flow characteristics, innovatively proposed two electrolyte flow schemes under the vertical machining mode; Then, based on the above two flow channel structures and the energy loss characteristics of viscous fluid during liquid phase mass transfer, a mathematical model of liquid phase mass transfer flow field is established, which combines the viscosity loss characteristics of electrolyte, and by introducing a optimized flow channel structure that combined with the characteristics of positive flow and side flow and adjusting the parameters of electrolyte inlet / outlet, the optimal design channel structure and uniform flow field of aero-rotor blades are realized. Finally, the accuracy and rationality of the proposed scheme are verified by electrochemical machining verification test, which lays a research foundation and guarantee for the feasibility and accuracy of vertical electrochemical machining machine tool in aero-rotor blades.

\section{Analysis and design of vertical electrochemical machining flow field characteristics of aero-rotor blades}

\subsection{Analysis of vertical electrochemical machining flow}

\section{field characteristics of aero-rotor blades}

\subsubsection{Mechanism of flow field}

The flow rate of electrolyte plays a key role in the process of controlling the corresponding etching process through liquid mass transfer in each part of the machining gap. On the one hand, in order to strengthen the liquid mass transfer process and ion reaction process in the machining gap, it is necessary to make the flow field in the machining gap have a higher flow rate in the turbulent state; On the other hand, according to the Deconinck [13] found in the electrochemical energy and bubble rate accumulated along the process will be produced by liquid mass transfer and gas-liquid two-phase flow in the processing gap, and the coupling effect of these products will affect the final forming quality by acting on the conductivity of electrolyte, so the higher electrolyte flow rate is helpful to ensure the smooth discharge of electrolytic products. The pressure of the electrolyte at the inlet is an important condition for the electrolyte to have a certain speed; In addition, when the electrolyte temperature in the machining gap is too high, so the electrolyte may appear partial boiling or even evaporation in the gap, while when the electrolyte temperature is too low, the anode surface may produce passivation phenomenon. Therefore, it is necessary to control the temperature of machining gap through the change of flow rate. Meanwhile, considering that the pressure of the electrolyte at the inlet is an important guarantee for the electrolyte to have a certain speed, so the following temperature rise criteria and turbulence criteria for the electrolyte to controlling the flow rate are established.

Criteria I: according to the formula (1), control the temperature rise to determine the inlet velocity of the machining gap:

$$
u_{0}=\frac{i^{2}}{\rho_{l} \kappa_{0} C_{l} \Delta T} L
$$

In above formula, $i$ represents the current density; $u_{0}$ represents the inlet velocity of the electrolyte; $\kappa_{0}$ represents the initial conductivity of the electrolyte; $L$ represents the length of the electrolyte flow, $\Delta T$ represents the temperature rise of the electrolyte; $\rho_{l}$ represents the density of the electrolyte; $C_{l}$ represents the heat capacity of the electrolyte.

Criteria II: in order to ensure that the electrolyte is in a turbulent state, the corresponding flow rate should meet the following formula:

$$
u_{\mathrm{Re}}>2300 \frac{v}{D_{h}}
$$

In above formula, Re represents the Reynolds number; $D_{h}$ represents the hydraulic diameter; $v$ represents the kinematic viscosity of electrolyte. 
The flow rate of the machining gap can be determined by combining above two criteria:

$$
u \geq \max u_{\mathrm{Re}}, u_{0}
$$

In order to ensure that the electrolyte in the gap has sufficient flow rate, it is necessary to add a certain pressure at the inlet of the gap. The value should be the sum of dynamic pressure, viscous friction force and outlet back pressure, so the input pressure corresponding to the inlet velocity is obtained from the Bernoulli equation of the actual fluid as shown in the Table 1.

$$
P_{A}+\frac{a_{A} \rho_{l} u_{0}^{2}}{2 g}+\rho_{l} Z_{A}=P_{B}+\frac{a_{B} \rho_{l} u^{2}}{2 g}+\rho_{l} Z_{B}+\rho_{l} \sum H
$$

In above formula, $a_{A}$ and $a_{B}$ are the flow parameters of the gap inlet and outlet, respectively; and $\sum H$ is the head loss of the fluid per unit weight.

Table 1 Boundary conditions

\begin{tabular}{ccc}
\hline$u_{0}(\mathbf{m} / \mathbf{s})$ & $P_{A}(\mathbf{M p a})$ & $P_{B}($ Mpa $)$ \\
\hline 15 & 1.476 & 0.2 \\
\hline
\end{tabular}

\subsubsection{Mathematical model of flow field}

In order to ensure that the movement of the electrolyte in the above electrolytic flow channel is turbulent and considering that the electrolyte used should have Newtonian fluid characteristics of low molecular compound solution (in this paper, In 718 super-alloy was used as the blade material and $10 \%$ sodium nitrate solution was used as the electrolyte), In this paper, the mass continuity equation (as shown in formula 5) and momentum conservation model (as shown in formula 6) of viscous Newtonian fluid were established; a certain instantaneous velocity $u$ in the above two turbulent motion models was replaced by the sum of the average velocity $\bar{u}$ and fluctuating velocity $u$ at this time and the above two models are combined and time-homogenized to transform into the corresponding Reynolds equation (as shown in formula 7); Because formula 7 introduces a variable with a pulsating velocity correlation distance and represents the dynamic transport rate per unit area of the traversing fluid caused by turbulent vortex pulsation, in order to ensure the solvability of the variable, based on the modified zero-square model $\quad\left(k^{1 / 2}=\sqrt{u_{i} u_{i} / 2} \quad \varepsilon=\frac{v}{\rho_{l}} \overline{\left(\frac{\partial u_{i}}{\partial x_{k}}\right)\left(\frac{\partial u_{i}}{\partial x_{k}}\right)}\right)$ proposed by Kolmogorov [14] and the generalized turbulent transport parameter model $\left(Z=k^{m} l^{n}\right)$ established by circuitous tactics, the solvable flow field model for viscous Newtonian fluid in runner motion is obtained (as shown in formula 8).

$$
\frac{\partial \rho_{l}}{\partial t}+\frac{\partial\left(\rho_{l} u_{x}\right)}{\partial x}+\frac{\partial\left(\rho_{l} u_{y}\right)}{\partial y}+\frac{\partial\left(\rho_{l} u_{z}\right)}{\partial z}=0
$$

In above formula, $u_{x}, u_{y}, u_{z}$ represents the components of velocity $u$ on $\mathrm{x}$ axis, $\mathrm{y}$ axis and $\mathrm{z}$ axis, respectively.

$$
\left\{\begin{array}{l}
\frac{\partial u_{x}}{\partial t}+u_{x} \frac{\partial u_{x}}{\partial x}+u_{y} \frac{\partial u_{x}}{\partial y}+u_{z} \frac{\partial u_{x}}{\partial z}=f_{x}-\frac{1}{\rho_{l}} \frac{\partial p}{\partial x}+v\left[\frac{\partial^{2} u_{x}}{\partial x^{2}}+\frac{\partial^{2} u_{x}}{\partial y^{2}}+\frac{\partial^{2} u_{x}}{\partial z^{2}}\right] \\
\frac{\partial u_{y}}{\partial t}+u_{x} \frac{\partial u_{y}}{\partial x}+u_{y} \frac{\partial u_{y}}{\partial y}+u_{z} \frac{\partial u_{y}}{\partial z}=f_{y}-\frac{1}{\rho_{l}} \frac{\partial p}{\partial y}+v\left[\frac{\partial^{2} u_{y}}{\partial x^{2}}+\frac{\partial^{2} u_{y}}{\partial y^{2}}+\frac{\partial^{2} u_{y}}{\partial z^{2}}\right] \\
\frac{\partial u_{z}}{\partial t}+u_{x} \frac{\partial u_{z}}{\partial x}+u_{y} \frac{\partial u_{z}}{\partial y}+u_{z} \frac{\partial u_{z}}{\partial z}=f_{z}-\frac{1}{\rho_{l}} \frac{\partial p}{\partial z}+v\left[\frac{\partial^{2} u_{z}}{\partial x^{2}}+\frac{\partial^{2} u_{z}}{\partial y^{2}}+\frac{\partial^{2} u_{z}}{\partial z^{2}}\right]
\end{array}\right.
$$

In above formula, $f_{x}$ represents the mass force of the electrolyte; $p$ represents the pressure of the electrolyte, $v$ represents the viscosity of electrolyte.

$$
\begin{aligned}
& \left\{\begin{array}{l}
\frac{\partial \overline{u_{x}}}{\partial t}+\overline{u_{x}} \frac{\partial \overline{u_{x}}}{\partial x}+\overline{u_{y}} \frac{\partial \overline{u_{x}}}{\partial y}+\overline{u_{z}} \frac{\partial \overline{u_{x}}}{\partial z}=f_{x}-\frac{1}{\rho_{l}} \frac{\partial \bar{p}}{\partial x}+v \mathrm{~V}^{2} u_{x}-\frac{\partial \overline{u_{x} \overline{u_{x}}}}{\partial x}-\frac{\partial \overline{u_{y} \overline{u_{x}}}}{\partial y}-\frac{\partial \overline{u_{z} \overline{u_{x}}}}{\partial z} \\
\frac{\partial \overline{u_{y}}}{\partial t}+\overline{u_{x}} \frac{\partial \overline{u_{y}}}{\partial x}+\overline{u_{y}} \frac{\partial \overline{u_{y}}}{\partial y}+\overline{u_{z}} \frac{\partial \overline{u_{y}}}{\partial z}=f_{y}-\frac{1}{\rho_{l}} \frac{\partial \bar{p}}{\partial x}+v \nabla^{2} u_{y}-\frac{\partial \overline{u_{x} \overline{u_{y}}}}{\partial x}-\frac{\partial \overline{u_{y} \overline{u_{y}}}}{\partial y}-\frac{\partial \overline{u_{z} \overline{u_{y}}}}{\partial z} \\
\frac{\partial \overline{u_{z}}}{\partial t}+\overline{u_{x}} \frac{\partial \overline{u_{z}}}{\partial x}+\overline{u_{y}} \frac{\partial \overline{u_{z}}}{\partial y}+\overline{u_{z}} \frac{\partial \overline{u_{z}}}{\partial z}=f_{y}-\frac{1}{\rho_{l}} \frac{\partial \bar{p}}{\partial x}+v \mathrm{~V}^{2} u_{z}-\frac{\partial \overline{\bar{u}_{x} \overline{u_{z}}}}{\partial x}-\frac{\partial \overline{u_{y} \overline{u_{z}}}}{\partial y}-\frac{\partial \overline{u_{z} \overline{u_{z}}}}{\partial z}
\end{array}\right. \\
& \left\{\begin{array}{c}
\frac{\partial\left(\rho_{l} k\right)}{\partial t}+\frac{\partial\left(\rho_{l} k u_{i}\right)}{\partial t}=\frac{\partial}{\partial x_{j}}\left[\left(v+\rho_{l} C_{v} \frac{k^{2}}{\varepsilon \sigma_{k}}\right) \frac{\partial k}{\partial x_{j}}\right]-\rho_{l} \varepsilon+G_{k}+G_{b} \\
\frac{\partial\left(\rho_{l} \varepsilon\right)}{\partial t}+\frac{\partial\left(\rho_{l} k u_{i}\right)}{\partial t}=\frac{\partial}{\partial x_{j}}\left[\left(v+\rho_{l} C_{v} \frac{k^{2}}{\varepsilon \sigma_{\varepsilon}}\right) \frac{\partial \varepsilon}{\partial x_{j}}\right]+C_{1 \varepsilon} \frac{\varepsilon}{k}\left(G_{k}+C_{3 \varepsilon} G_{b}\right)-C_{2 \varepsilon} \rho_{l} \frac{\varepsilon^{2}}{k}
\end{array}\right.
\end{aligned}
$$

In above formula, $C_{v}$ represents the Empirical constants of fluid viscosity; $\sigma_{k}$ and $\sigma_{\varepsilon}$ are the Prandtl numbers corresponding to turbulent kinetic energy $k$ and dissipation rate $\varepsilon$, respectively; $G_{k}$ represents the generation term of turbulent kinetic energy $k$ caused by mass force, $G_{b}$ represents the generation term of turbulent kinetic energy $k$ caused by electrolyte pressure; $C_{1 \varepsilon}, C_{2 \varepsilon}, C_{3 \varepsilon}$ represents the model empirical constant [15], and its specific values are shown in Table 2.

Table 2 Value of empirical constants for flow channel turbulence model

\begin{tabular}{cccccc}
\hline $\begin{array}{c}\text { Model } \\
\text { constant }\end{array}$ & $C_{1 \varepsilon}$ & $C_{2 \varepsilon}$ & $C_{3 \varepsilon}$ & $\sigma_{k}$ & $\sigma_{\varepsilon}$ \\
\hline Value & 1.44 & 1.92 & 0.09 & 1.0 & 1.3 \\
\hline
\end{tabular}

\subsection{Design of vertical electrochemical machining flow field}

\section{structure of aero-rotor blades}

\subsubsection{Selection of Electrolyte Flow Mode}

According to the relationship between cathode and electrolyte flow, electrolyte flow can be divided into positive flow, side flow and reflux flow. In the process of traditional blade electrochemical machining, the side flow from the inlet (outlet) edge is usually adopted (as shown in Fig .1).

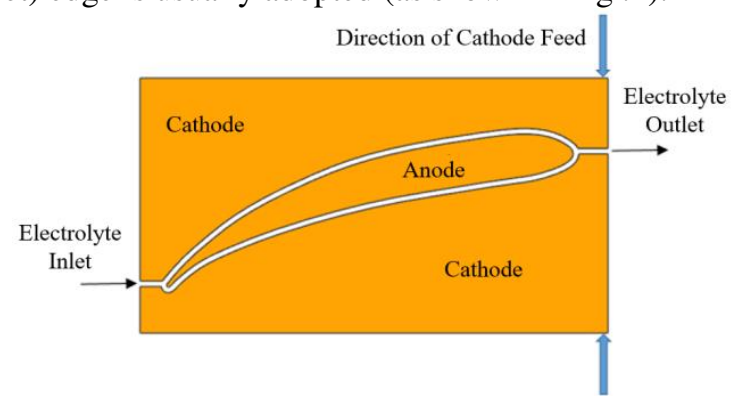

Fig .1 Schematic diagram of traditional side flow electrochemical machining blade 
The advantages of this electrolyte flow mode are more prominent in the processing of blades with less distortion on the surface. Because of the small distortion of the blades, the electrolyte flows smoothly in the flow channel, and the change of the electrolyte flow rate and flow pressure are slow and uniform. However, there are still some defects in this flow mode that need to be optimized. As shown in Fig. 2, when the electrolyte flows through the blank, part of the electrolyte will rebound by the side of the blank, which makes the flow field very disordered at the entrance of the machining gap, resulting in unstable processing process, and the flow rate of electrolyte flowing through the blade basin and blade back are unpredictable and passive [16].

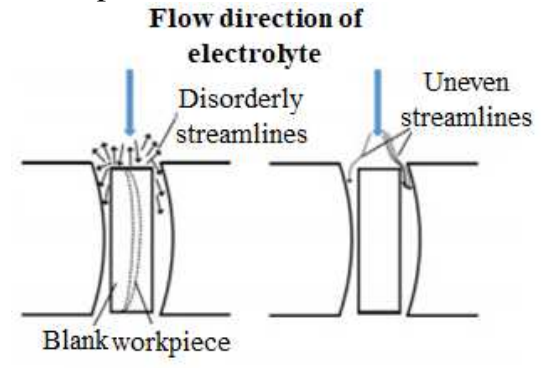

Fig .3(a) Schematic diagram of scheme 1 electrolyte flow

In order to solve the above problems, combined with the structure of vertical electrolytic machining machine tool, the processing mode of blade basin and blade back is adopted respectively (this paper taking the processing of blade back surface as an example), which can control the electrolyte flow rate, meanwhile, the processing of unidirectional feed machine tool in spindle is realized. In this paper, two electrolyte flow modes are designed as shown in figure 3.4. Scheme one electrolyte flows from the spindle to the gap between the blade edge and the cathode through the liquid hole above the cathode, and finally flows out from the tip. Therefore, two electrolyte flow modes (as shown in Fig. 3) are designed in this paper, that is, scheme 1: electrolyte flows from the main axis, through the over-liquid hole above the cathode into the gap between the blade edge and the cathode, and from the end of the blade to the blade body, finally from the tip of the blade; Scheme 2: electrolyte flows from the main axis to the overliquid hole of the cathode side, both sides flow to the blade body at the same time, and then from the tip of the blade.

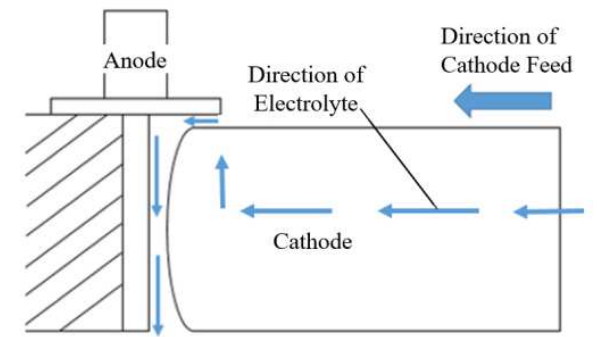

Fig .3(a) Schematic diagram of scheme 1 electrolyte flow



Fig .3(b) Schematic diagram of scheme 2 electrolyte flow

\subsubsection{Design of cathode tool flow channel structure}

The flow field simulation analysis is based on the distribution of electrolyte in the flow channel, so it is necessary to construct the solid model of electrolyte distribution. First of all, the cathode structure is designed. In order to ensure that the liquid in the channel is sufficient and has a certain back pressure, the area of the liquid outlet should meet the requirements of less than the area of the inlet and larger than the area of the outlet. Combined with the above flow mode, the corresponding cathode structures were shown in figure 4.

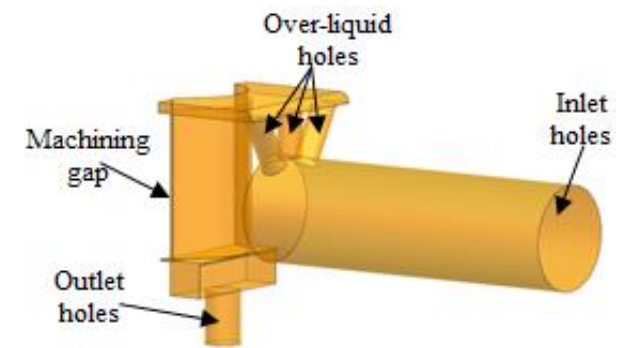

(a) Flow structure of scheme 1

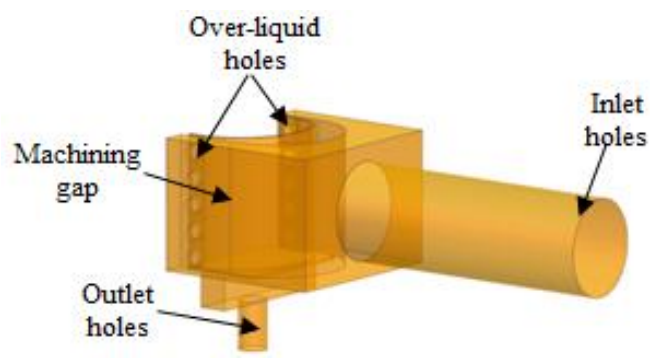

(b) Flow structure of scheme 2

Fig. 5 Cathode tool flow channel structure

\subsubsection{Design of fixture flow channel structure}

The fixture must be a well sealed cavity so that the electrolyte can maintain a high flow rate through the machining gap in order to smoothly discharge the anodic dissolution products and processing heat to ensure the stability of the processing process. At the same time, in the process of electrolytic processing, the flow mode of electrolyte depends on the design of fixture, so this paper designs the blade machining fixture for vertical machine tool (as shown in Fig. 6) based on the above two electrolyte flow modes and according to the size of inlet, outlet and the relationship between inlet area, outlet area and over-liquid area. 


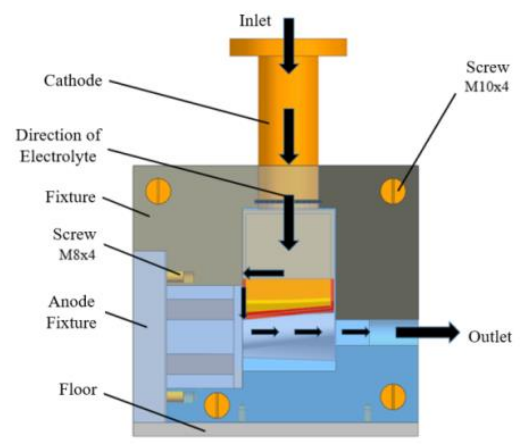

(a) Electrolyte flow mode for scheme 1

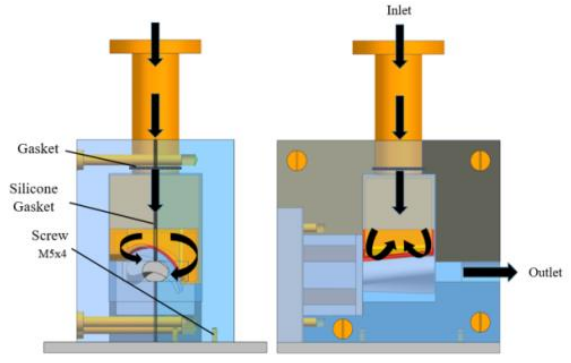

(b) Electrolyte flow mode for scheme 2

Fig. 6 Fixture flow channel structure

\section{Results and discussion}

Based on the above three-dimensional model and mathematical models of the flow channel, the following results about the flow parameters are obtained by numerical simulation, and the initial flow field structure is optimized based on the results.

\subsection{Initial flow field analysis of aero-rotor blades for}

\section{vertical electrochemical machining}

In the pressure analysis of flow field: Fig .7(a) and Fig .7(b) are the pressure distribution clouds when the electrolyte enters the flow channel of the scheme 1 and scheme 2 , respectively. In scheme 1, the pressure decreases obviously when the electrolyte flows into the machining gap, and the sudden change of the pressure is easy to produce cavities phenomenon. In contrast, in the scheme 2, the change of the pressure gradient is more uniform when the electrolyte flows into the machining gap.

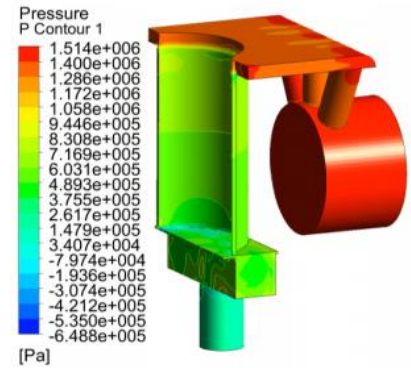

(a) Cloud diagram of electrolyte flow pressure distribution for scheme 1

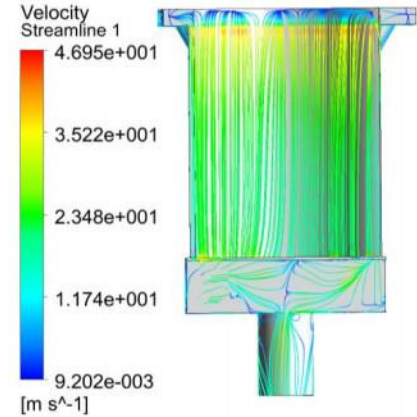

(c) Cloud diagram of electrolyte flow streamline distribution for scheme 1



(e) Cloud diagram of electrolyte flow velocity vector distribution for scheme 1

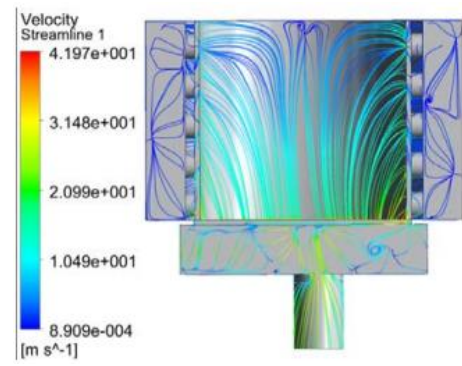

(d) Cloud diagram of electrolyte flow streamline distribution for scheme 2

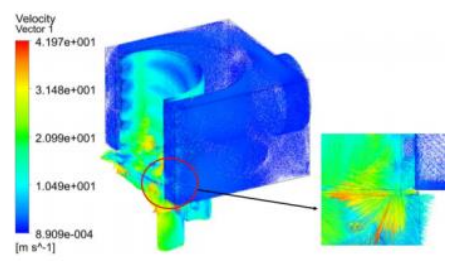

(f) Cloud diagram of electrolyte flow velocity vector distribution for scheme 1
Fig. 7 Cloud diagram of electrolyte flow field parameters distribution (Initial flow field)

In the flow velocity analysis of flow field: Fig. 7(c) and Fig. 7(d) are the streamline distribution diagrams when the electrolyte enters the flow channel of the scheme 1 and scheme 2, respectively. It can be seen that the velocity of electrolyte in the machining gap of scheme 1 is about $25 \mathrm{~m} / \mathrm{s}$, and meet the turbulence condition, but when the electrolyte just flows into the machining gap, the velocity mutation is large and the distribution is not uniform; However, in scheme 2 , the flow rate of the electrolyte in the machining gap is about $10 \mathrm{~m} / \mathrm{s}$, which can not meet the turbulence condition. At the same time, the velocity of the electrolyte increases with the increase of the length of the process and the vortex phenomenon occurs at the maximum curvature of the back of the blade, which will also lead to insufficient supply. Fig. 7(e) and Fig. 7(f) are the velocity vector diagrams when the electrolyte enters the flow channel of the scheme 1 and scheme 2, respectively. It can be observed that the streamline direction of the electrolyte at the entrance of the machining gap is messy and has a certain effect on the stability of the machining. While in the scheme 2, the messy streamline appears at the electrolyte outlet of the machining gap and is mainly concentrated in the non-processing area, so this streamline distribution mode has little effect on the flow field stability in the machining gap. By analyzing the flow field distribution of the above two flow channel structures, it can be seen that the velocity of electrolyte in the machining gap of scheme 1 is higher than that of scheme 2 and the liquid supply is sufficient, while the gap flow field of scheme 2 is more stable than that of scheme 1 . 


\subsection{Optimization of initial flow field in vertical}

\section{electrochemical machining of aero-rotor blades}

\subsubsection{Optimization of initial flow field structure in vertical}

\section{electrochemical machining of aero-rotor blades}

To sum up, in order to ensure the stability of the flow field and the flow rate of the electrolyte at the same time, the problem of insufficient electrolyte supply at the large curvature of the blade back in scheme 2 was first optimized by introducing the electrolyte flow channel structure of scheme 1 in this paper (as shown in Fig. 8(a)), and the numerical simulation analysis of the optimized flow channel is carried out. As shown in Fig. 8(c), it can be seen that the overall pressure distribution uniformity of the electrolyte in the machining gap is further improved, and there is no sudden pressure drop and negative pressure in the machining gap. While in Fig. 8(d), it can be seen that the electrolyte in the machining gap is sufficient, and the electrolyte decreases significantly in the disorderly area of the outlet, thus further improving the stability of the electrolyte flow in the whole processing gap.

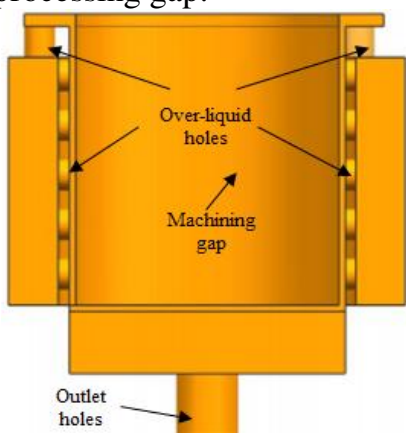

(a) Structure of optimized flow channel (front view)

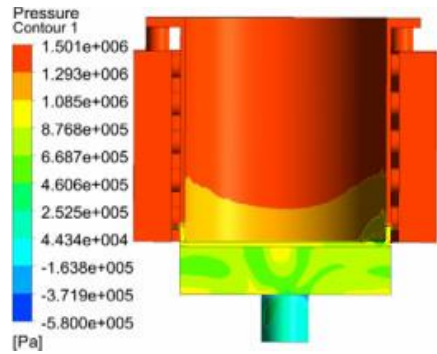

(c) Cloud diagram of electrolyte flow pressure distribution for optimized flow channel

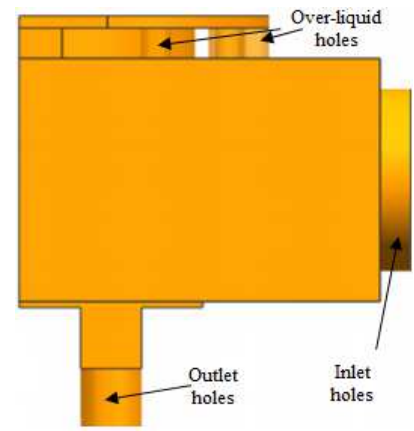

(b) Structure of optimized flow channel (side view)

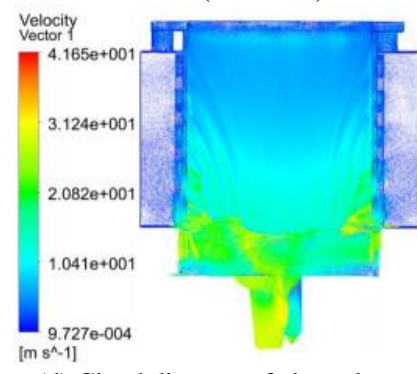

(d) Cloud diagram of electrolyte velocity distribution for optimized flow channel
Fig. 8 Optimization of flow channel structure of scheme 2

\subsubsection{Optimization of initial flow field structure in vertical}

\section{electrochemical machining of aero-rotor blades}

The flow field analysis of the optimized flow channel structure shows that the corresponding velocity is small under the premise of the stability of the flow field. It is concluded that the main reason for this phenomenon is that in the design of simulation parameters of the initial flow field, the flow velocity calculated by Bernoulli equation is the ideal flow velocity without considering the influence of fluid viscosity. Therefore, to meet the above simulation conditions, higher inlet velocity is needed to counteract the decrease of actual velocity due to viscous force. In order to ensure the stability of the flow field in the machining gap, the flow rate can meet the purpose of the above turbulence by changing the pressure matching value of the inlet and outlet, and the control variable method is used to divide the pressure into three degrees: high, medium and low, so as to find the optimal pressure matching value (as shown in Table 3 ).

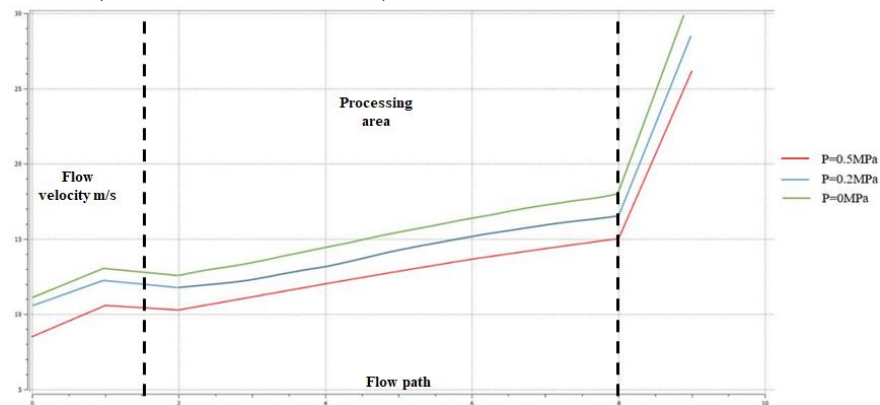

(a) Flow rate of interstitial electrolyte under different outlet pressure (Local)

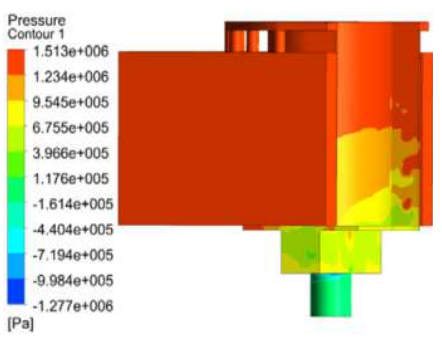

(b) $P_{\mathrm{B}}=0 \mathrm{MPa}$

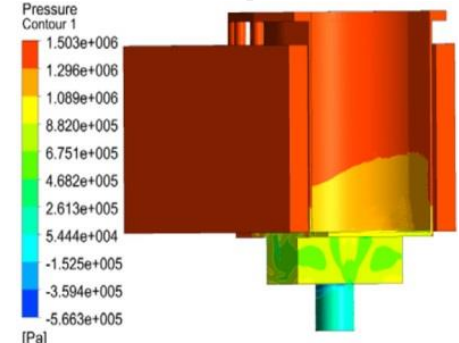

(c) $P_{\mathrm{B}}=0.2 \mathrm{MPa}$

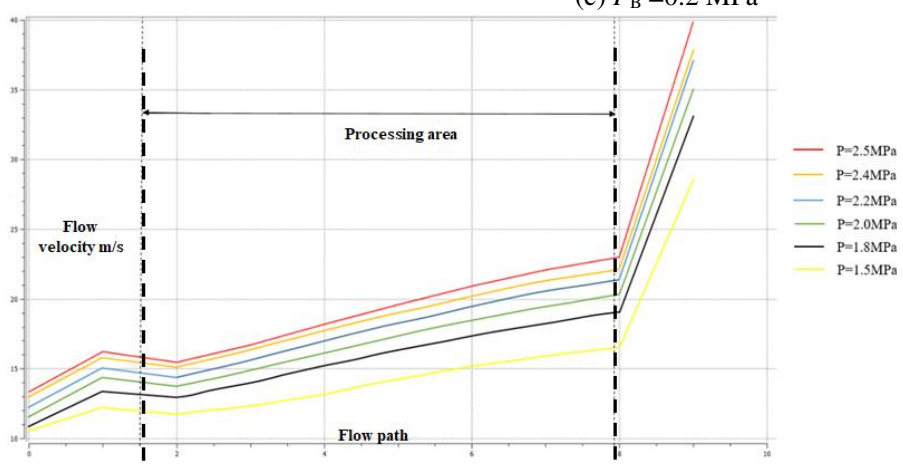

(d) Flow rate of interstitial electrolyte under different inlet pressure (Local)

Fig. 9 Analysis of the relationship between different process parameters and flow field

Table 3 Flow optimization parameters

\begin{tabular}{ccc}
\hline$u_{0}(\mathbf{m} / \mathbf{s})$ & $P_{A}(\mathbf{M p a})$ & $P_{B}(\mathbf{M p a})$ \\
\hline 15 & 2.4 & 0.2
\end{tabular}

According to Table 1, the inlet pressure $P_{\mathrm{A}}$ is $1.5 \mathrm{MPa}$, and the outlet pressure is changed. According to Fig. 9(a), with the increase of outlet pressure, the flow rate in the machining gap decreases gradually, and the electrolyte flow rate is the largest when the outlet pressure is $0 \mathrm{MPa}$, while the uniformity of electrolyte flow rate increases with the increase of outlet pressure (as shown in Fig. 9(b-c)). Therefore, under the 
condition of uniform gap electrolyte pressure distribution, a higher gap electrolyte flow rate, $P_{\mathrm{B}}=0.2 \mathrm{MPa}$., is selected.

According to Table 1 , the outlet pressure $P_{\mathrm{B}}$ is $0.2 \mathrm{MPa}$, and the inlet pressure is changed. According to Fig. 9(d), with the increase of inlet pressure, the flow rate in the machining gap increases gradually, and when the inlet pressure $P_{\mathrm{A}} \geq 2.4$ $\mathrm{MPa}$, the electrolyte flow rate of the machining gap meets the turbulence condition, and the electrolyte velocity increases along the gap flow, which is beneficial to the discharge of electrolyte products and bubbles. Therefore, the inlet pressure should be more than $2.4 \mathrm{MPa}$, but the excessive electrolyte flow rate may cause unstable effects such as cathodic vibration during processing, so the inlet pressure $P_{\mathrm{A}}=2.4 \mathrm{MPa}$. is selected, which combines the maximum value of the pressure pump of the machine tool at the same time.

Therefore, the flow field of the blade back surface and the blade basin surface are optimized by this method, and the corresponding optimized flow field simulation results are obtained as shown in Fig. 10.

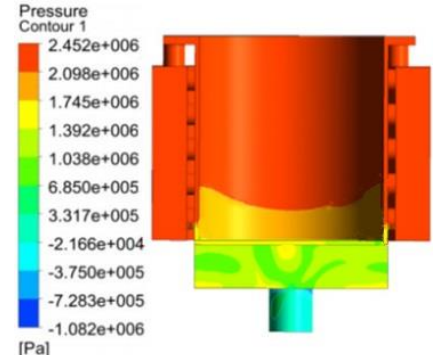

(a) Cloud diagram of electrolyte flow pressure distribution for blade back flow channel

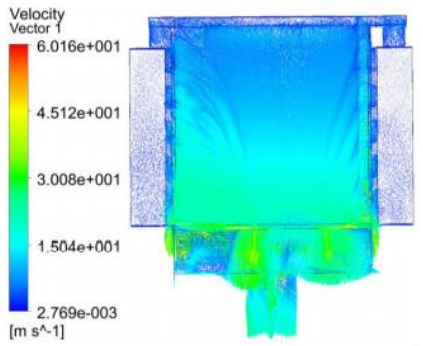

(c) Cloud diagram of electrolyte velocity distribution for blade back flow channel

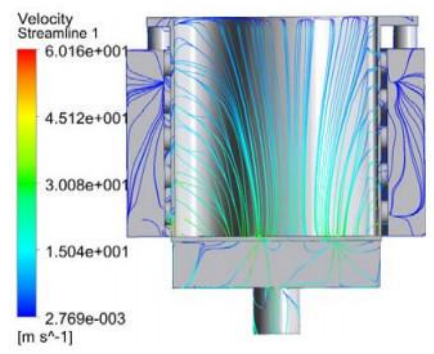

(e) Cloud diagram of electrolyte flow streamline distribution for blade basin flow channel

Fig. 10 Analysis of optimal flow field of aero-rotor blades

\subsection{Process verification of optimized flow field for aero-rotor}

blades

In order to verify the rationality of the above optimization scheme, the original (as shown in Fig. 11(a)) and optimized flow channel (as shown in Fig. 11(b)) of scheme 2 and the corresponding fixture (as shown in Fig. 11(c)) are used in this paper, and the surface error (as shown in Fig. 11(e-f)) and surface roughness (as shown in Table 4) of aero-rotor blade were analyzed by using three coordinate measuring instrument and roughness measuring instrument, respectively.

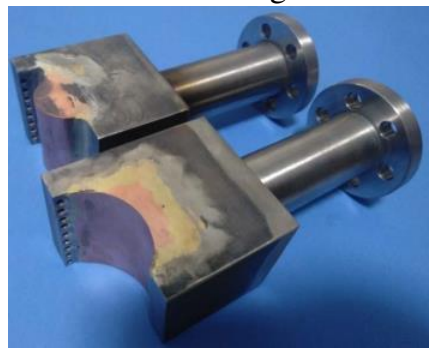

(a) Initial flow channel

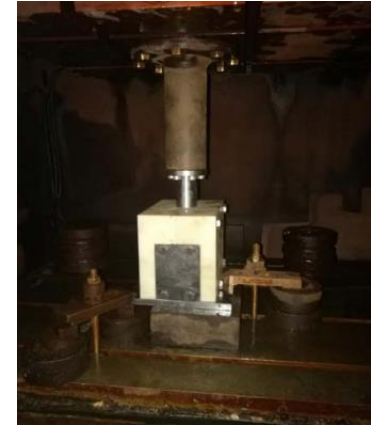

(c) Fixture

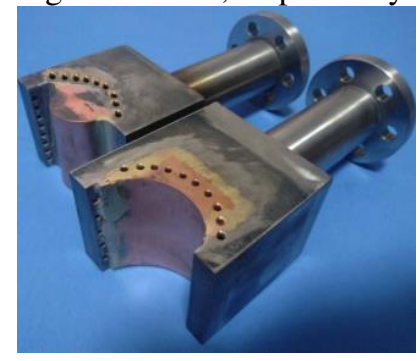

(b) Optimized flow channel

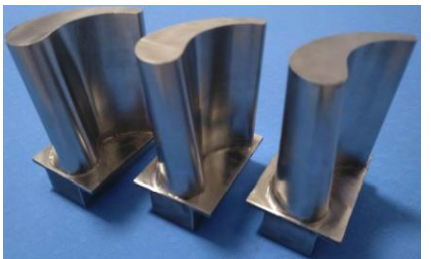

(d) Final products

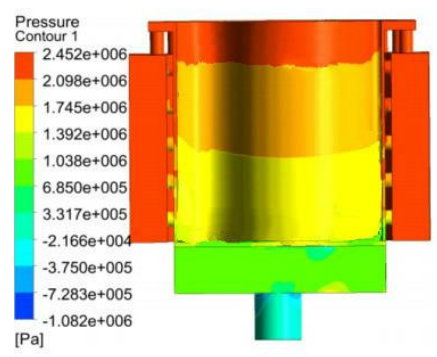

(d) Cloud diagram of electrolyte flow pressure distribution for blade basin flow channel

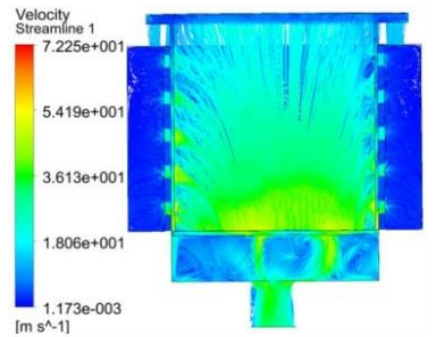

(f) Cloud diagram of electrolyte velocity distribution for blade basin flow channel



(e) Surface error of blade basin

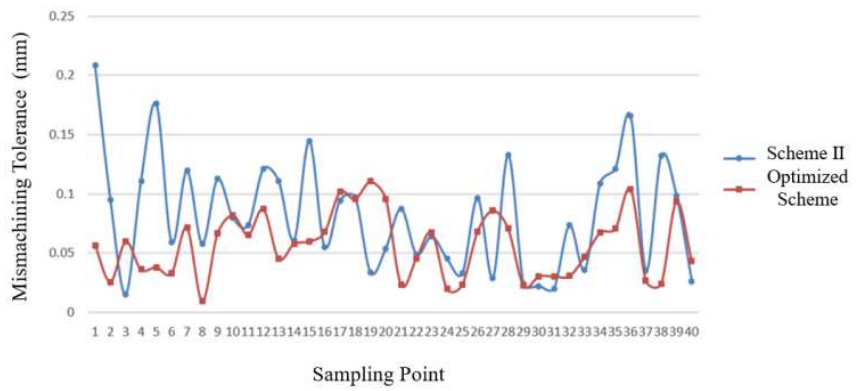

(f) Surface error of blade back

Table 4(a) Blade surface roughness of initial scheme 2

\begin{tabular}{cccc}
\hline Number of & Roughnes & Number of & Roughness/ \\
sampling & $\mathrm{s} / \mu \mathrm{m}$ & sampling & $\mu \mathrm{m}$ \\
\hline
\end{tabular}




\begin{tabular}{cccc}
\hline points & \multicolumn{3}{c}{ points } \\
\hline $\mathbf{1}$ & 1.31 & $\mathbf{1 1}$ & 2.58 \\
$\mathbf{2}$ & 1.41 & $\mathbf{1 2}$ & 1.91 \\
$\mathbf{3}$ & 1.47 & $\mathbf{1 3}$ & 1.68 \\
$\mathbf{4}$ & 1.36 & $\mathbf{1 4}$ & 2.57 \\
$\mathbf{5}$ & 0.96 & $\mathbf{1 5}$ & 2.68 \\
$\mathbf{6}$ & 0.89 & $\mathbf{1 6}$ & 1.96 \\
$\mathbf{7}$ & 1.54 & $\mathbf{1 7}$ & 2.54 \\
$\mathbf{8}$ & 1.08 & $\mathbf{1 8}$ & 2.04 \\
$\mathbf{9}$ & 1.37 & $\mathbf{1 9}$ & 2.69 \\
$\mathbf{1 0}$ & 1.03 & $\mathbf{2 0}$ & 2.13 \\
\hline
\end{tabular}

Table 4(b) Blade surface roughness of optimized scheme 2

\begin{tabular}{cccc}
\hline $\begin{array}{c}\text { Number of } \\
\text { sampling } \\
\text { points }\end{array}$ & $\begin{array}{c}\text { Roughnes } \\
\text { s/ } \mathbf{\mu m}\end{array}$ & $\begin{array}{c}\text { Number of } \\
\text { sampling } \\
\text { points }\end{array}$ & $\begin{array}{c}\text { Roughness/ } \\
\mathbf{\mu m}\end{array}$ \\
\hline $\mathbf{1}$ & 1.20 & $\mathbf{1 1}$ & 1.09 \\
$\mathbf{2}$ & 1.28 & $\mathbf{1 2}$ & 1.08 \\
$\mathbf{3}$ & 1.30 & $\mathbf{1 3}$ & 0.97 \\
$\mathbf{4}$ & 0.93 & $\mathbf{1 4}$ & 1.18 \\
$\mathbf{5}$ & 1.21 & $\mathbf{1 5}$ & 1.26 \\
$\mathbf{6}$ & 1.18 & $\mathbf{1 6}$ & 1.18 \\
$\mathbf{7}$ & 0.87 & $\mathbf{1 7}$ & 1.38 \\
$\mathbf{8}$ & 1.05 & $\mathbf{1 8}$ & 1.13 \\
$\mathbf{9}$ & 1.08 & $\mathbf{1 9}$ & 1.15 \\
$\mathbf{1 0}$ & 1.71 & $\mathbf{2 0}$ & 1.65 \\
\hline
\end{tabular}

The surface error range of the blade processed by the original scheme 2 is between $0.02-0.23 \mathrm{~mm}$, and the average error of the blade is $0.12 \mathrm{~mm}$, the larger error is mainly concentrated near the blade edge, and the simulation results are verified. While the error range of blade processed by the optimized scheme 2 is between is $0.02-0.12 \mathrm{~mm}$ and the average error of blade is $0.07 \mathrm{~mm}$, which has high accuracy. The average surface roughness of the blade processed by scheme 2 is $1.76 \mu \mathrm{m}$, and the surface roughness near the blade edge is low, and the average surface roughness of the blade processed by the optimized scheme is $1.16 \mu \mathrm{m}$, so the quasiconsistency and feasibility of the design idea are verified.

\section{Conclusion}

In order to ensure the stability and reasonable distribution of flow filed in aero-rotor blades vertical electrochemical machining, this paper combined with the traditional side flow processing blade flow characteristics, innovatively proposed two kinds of electrolyte flow schemes under the vertical machining mode; And then, based on the above two flow channel structures and the energy loss characteristics of viscous fluid during liquid phase mass transfer, a mathematical model of liquid phase mass transfer flow field is established, which combines the viscosity loss characteristics of electrolyte, and by introducing a optimized flow channel structure that combined with the characteristics of positive flow and side flow and the parameters of electrolyte inlet / outlet, the optimal design channel structure and uniform flow field of aero-rotor blades are realized. Finally, the accuracy and rationality of the proposed scheme are verified by electrochemical machining verification test, which lays a research foundation and guarantee for the feasibility and accuracy of vertical electrochemical machining machine tool in aero-rotor blades.

Acknowledgments This research is funded by National Natural Science Foundation of China (NSFC) under grant number 51705392, the project of 2019 Shaanxi Provincial Innovation Ability Support Program under grant number 2019PT-19.

Authors' contributions conceptualization, Liang Huang and Yan Cao; methodology, Liang Huang and Chunlei Tian; validation, Liang Huang, Yuanfei Wang and Jiang Du; formal analysis, Liang Huang and Chunlei Tian; investigation, Jiang $\mathrm{Du}$ and Ruochen Zhao; resources, Yuanfei Wang; writingoriginal draft preparation, Liang Huang and Yan Cao; writingreview and editing, Liang Huang; project administration, Yan Cao and Yuanfei Wang; funding acquisition, Yan Cao and Jiang Du.

Funding This research is funded by National Natural Science Foundation of China (NSFC) under grant number 51705392, the project of 2019 Shaanxi Provincial Innovation Ability Support Program under grant number 2019PT-19.

\section{Availability of data and materials}

The data used to support the findings of this study are available from the corresponding author upon request.

\section{Conflicts of Interest}

The authors declare that there are no conflicts of interest regarding the publication of this article.

\section{References}

1. Wang BW, Tang WZ, Song LK (2021) PSO-LSSVR: A surrogate modeling approach for probabilistic flutter evaluation of compressor blade. Structures 28: 1634-1645. https://doi.org/10.1016/j.istruc.2020.10.007.

2. Kozak N, Xu F, Rajanna MR (2020) High-Fidelity Finite Element Modeling and Analysis of Adaptive Gas Turbine Stator-Rotor Flow Interaction at Off-Design Conditions. J Mech., 36: 595-606. https://doi.org/10.1017/jmech.2020.28

3. Gu HY, Shaw AD, Amoozgar M (2020) Twist morphing of a composite rotor blade using a novel metamaterial. Compos. Struct., 254: 8-15. https://doi.org/10.1016/j.compstruct.2020.112855

4. Hao QL, Yang Q (2020) A self-adaptive auxiliary fixture for deformation control in blade machining. Int. J. Adv. Manuf. Tech., 2020, 111:1415-1423. https://doi.org/10.1007/s00170-020-06171-3

5.Gonzalez-Barrio H, Calleja-Ochoa A, (2020) Manufacturing Processes of Integral Blade Rotors for Turbomachinery, Processes and New Approaches. Appl Sci-Basel, 10: 1-15. https://doi.org/10.3390/app10093063. 
6. Zhao CH, Qu NS, Tang XC. (2019) Removal of adhesive powders from additive-manufactured internal surface via electrochemical machining with flexible cathode. Precis. Eng., 29: 569-578.

https://doi.org/10.1016/j.precisioneng.2020.11.003

7. Wang YD, Xu ZY, Hu JC (2020) Surface integrity analysis of electrochemical machining of gamma-TiAl alloys. Mater. Today Commun., 25: 7-14. https://doi.org/10.1016/j.mtcomm.2020.101686.

8. Zhu D, Hu XY, Lin JH (2020) Investigation into the bladeformation process in electrochemical trepanning of diffusers. Mach. Sci. Technol., 24: 489-507. https://doi.org/10.1080/10910344.2019.1701018

9. Xu ZY, Zhu D, Wang L (2008) Character of Flow Field on Turbine Blade with 3-Electrode Feeding Method in Electrochemical machining Chin., J. Mech., Eng-En., 44: 189-194. https://doi.org/10.3901/JME.2008.04.189

10. Liu J, Xu ZY, Wan LK (2013) Design and experiment of electrolyte flow mode in electrochemical machining of blisk. Acta Aeronauticaet Astronautica Sinica, 34: 259267.

https://doi.org/10.7527/S1000-6893.2013.0380

11. Sawicki J, Paczkowski J, (2015) Effect of the hydrodunamic conditions of electrolyte flow on critical states in electrochemical machining. The European Physical Journal Conference, 92: 02078. https://doi.org/10.1051/epjconf/20159202078

12. Chen YL, Zhou XC, Chen PX (2020) Electrochemical machining gap prediction with multi-physics coupling model based on two-phase turbulence flow. Chinese J. Aeronaut, 33: 1057-1063. https://doi.org/10.1016/j.cja.2019.03.006

13. Deconinck D, Van D, Albu C (2011) Study of the effects of heat removal on the copying accuracy of the electrochemical machining process. Electrochim. Acta, 56: 5642-5649. https://doi.org/10.1016/j.electacta.2011.04.021

14. Versteeg HK (2007) An introduction to computational fluid dynamic (The Finite Volume method). Pearson Education, UK.

15. Anjos RP, Medronho RD, Klein TS, Turbul J. (2020) Assessment of turbulence models for single phase CFD computations of a liquid-liquid hydrocyclone using OpenFOAM. 1: 32-40. https://doi.org/10.1080/14685248.2020.1846050

16. Xu JW, Zhu D, Lin JH, (2020) Flow field design and experimental investigation of electrochemical trepanning of diffuser with a special structure. Int. J. Adv. Manuf. Tech., 107: 1551-1558.

https://doi.org/10.1007/s00170-020-05091-6 
Figures

\section{Direction of Cathode Feed}

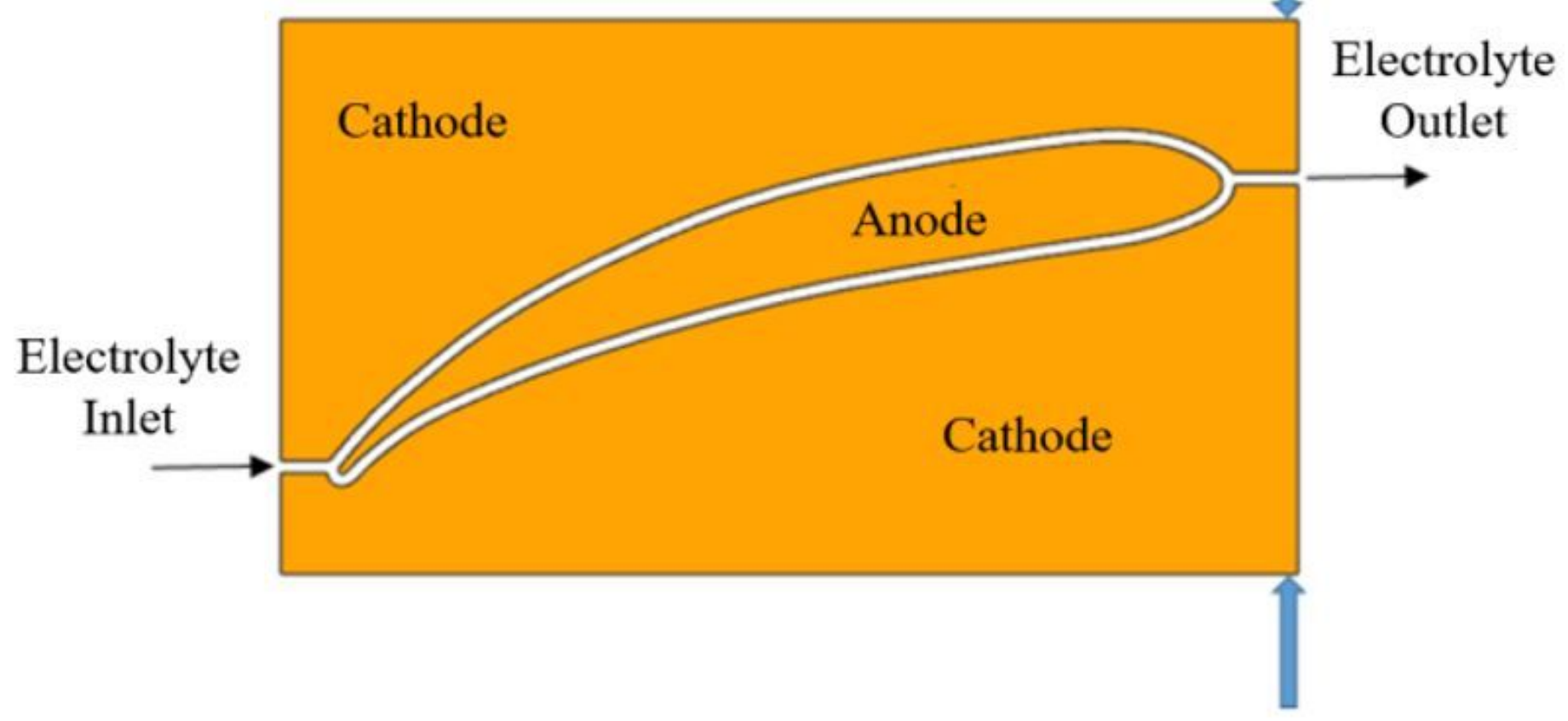

Figure 1

Schematic diagram of traditional side flow electrochemical machining blade 


\section{Flow direction of}

\section{electrolyte}

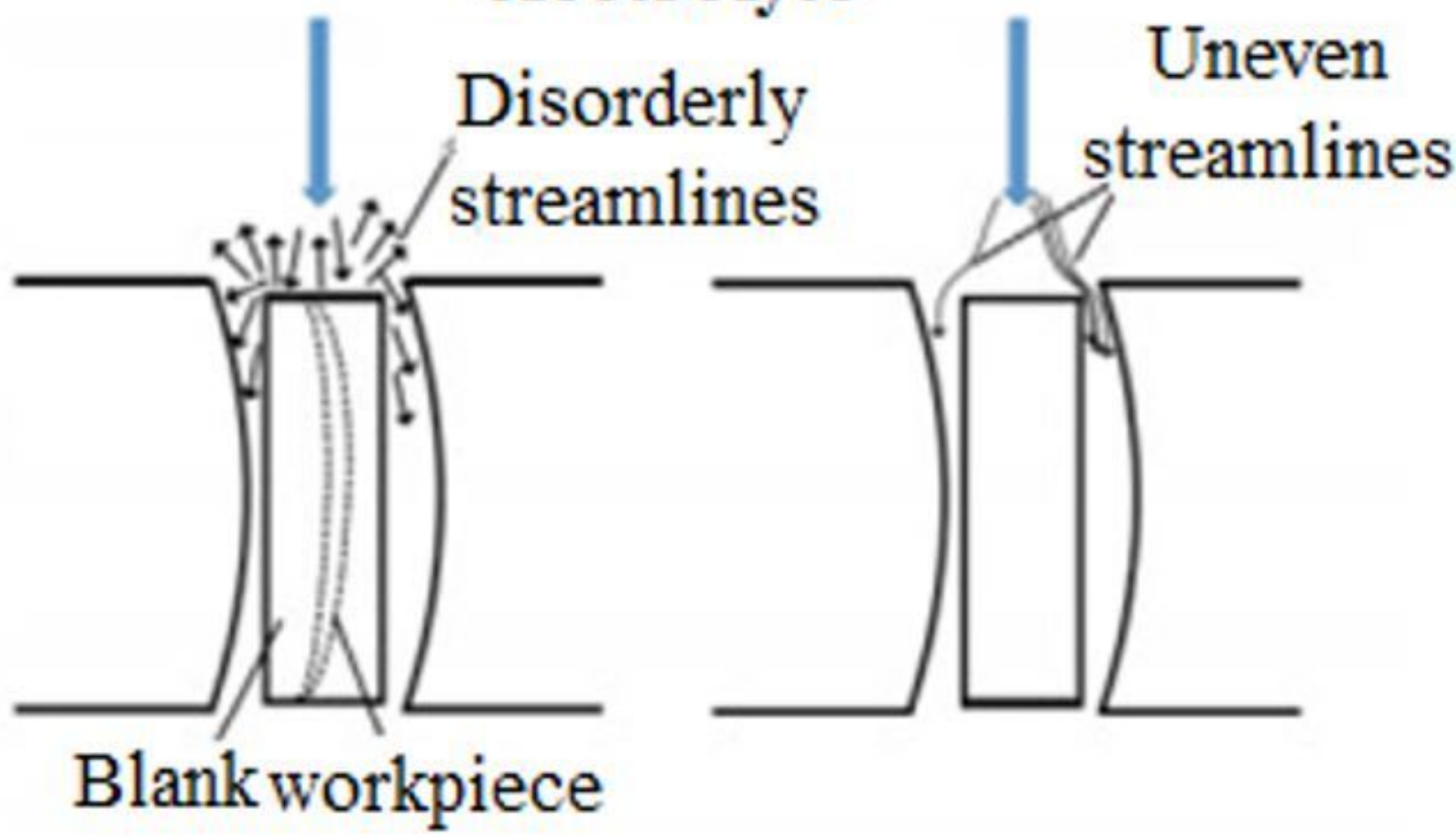

Figure 2

Schematic diagram of scheme 1 electrolyte flow

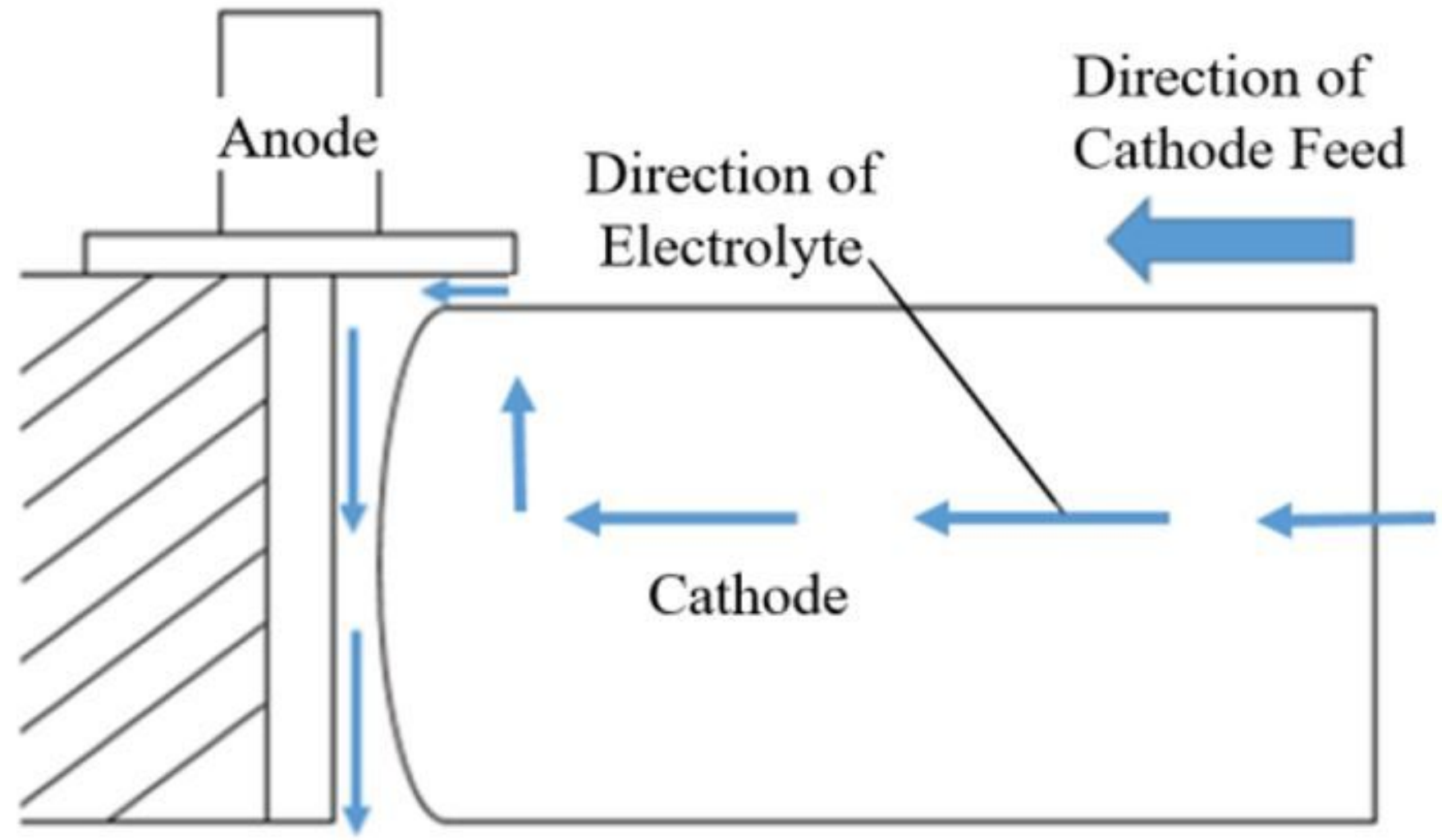


Figure 3

Schematic diagram of scheme 1 electrolyte flow

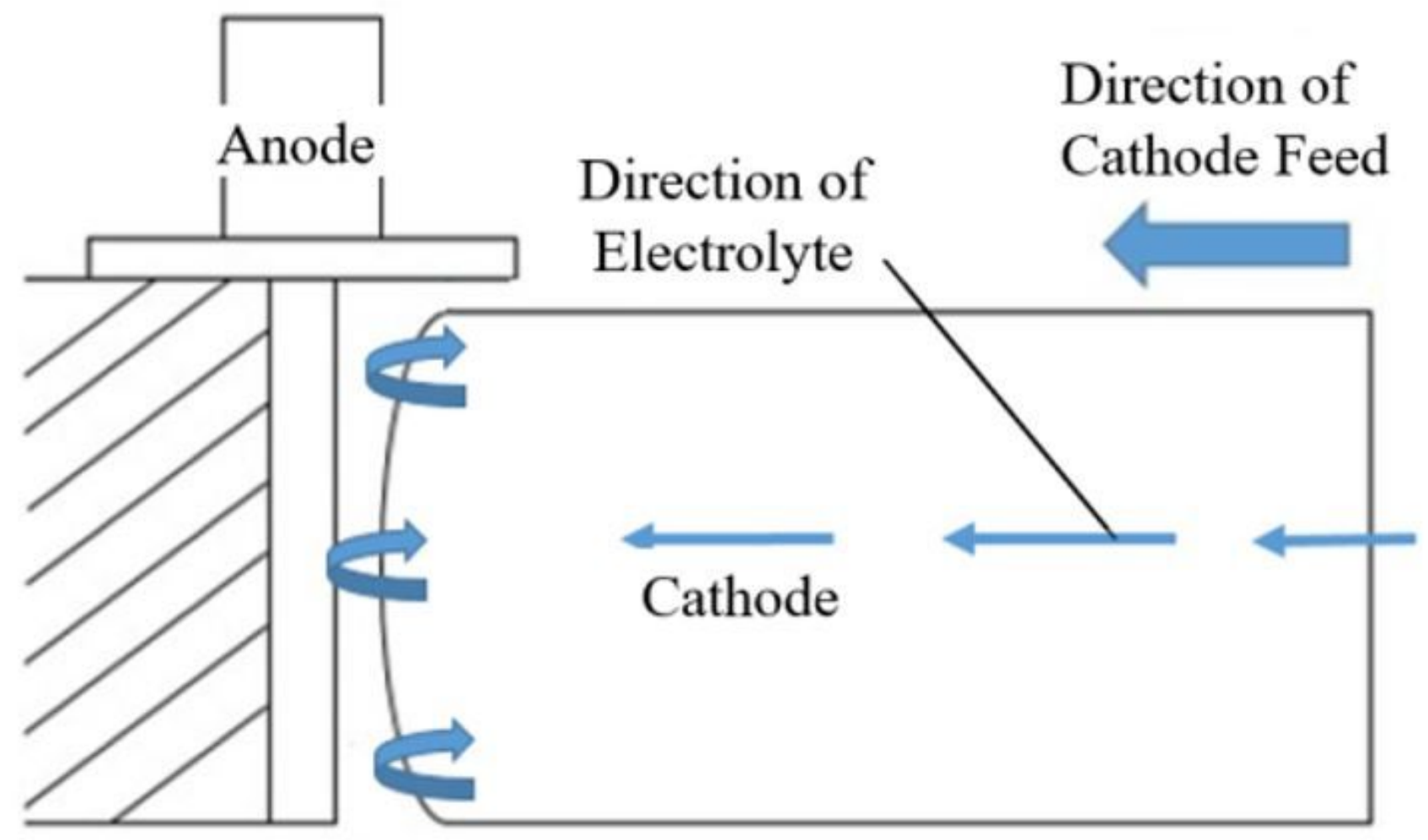

Figure 4

Schematic diagram of scheme 2 electrolyte flow 


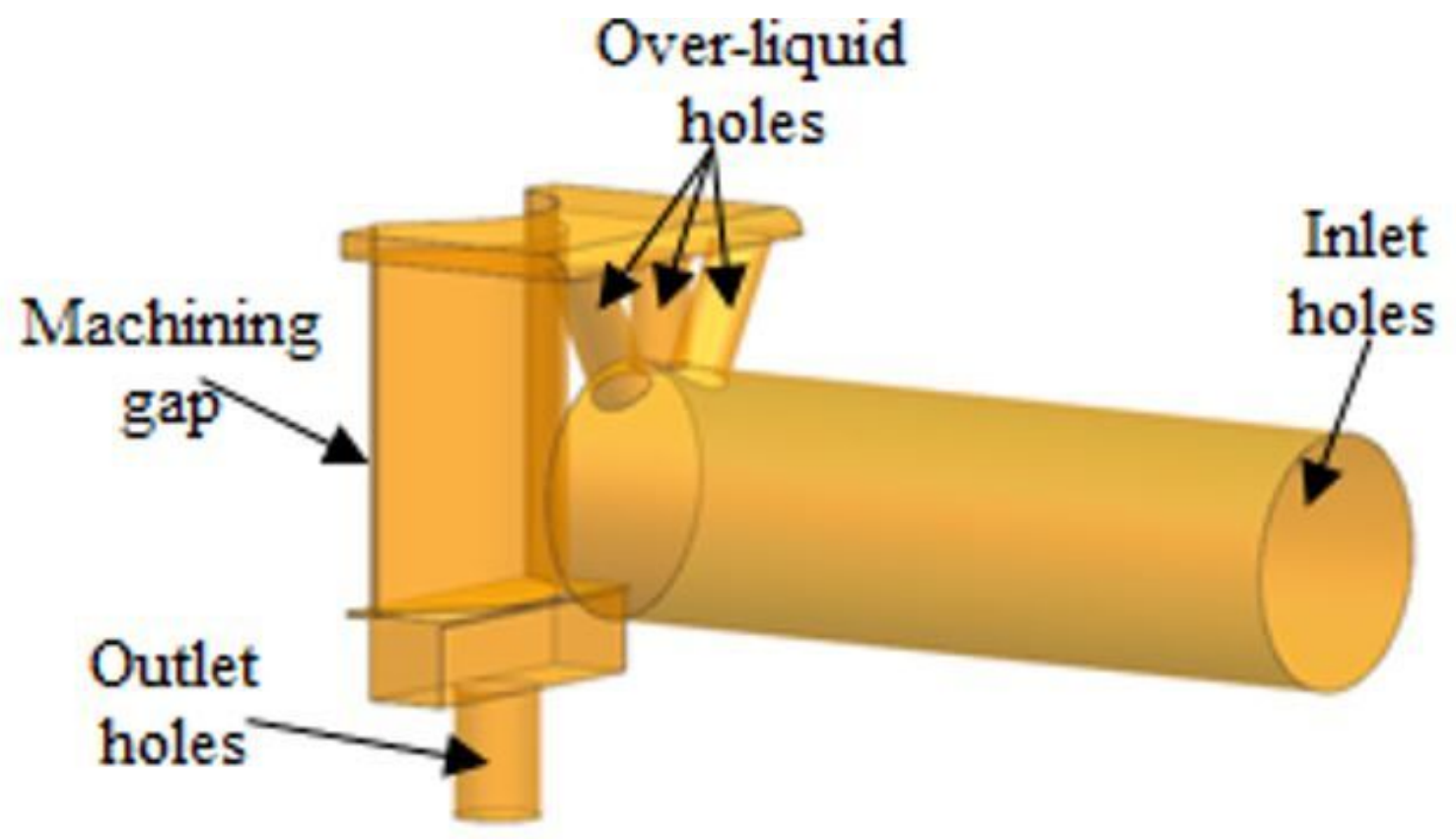

(a) Flow structure of scheme 1

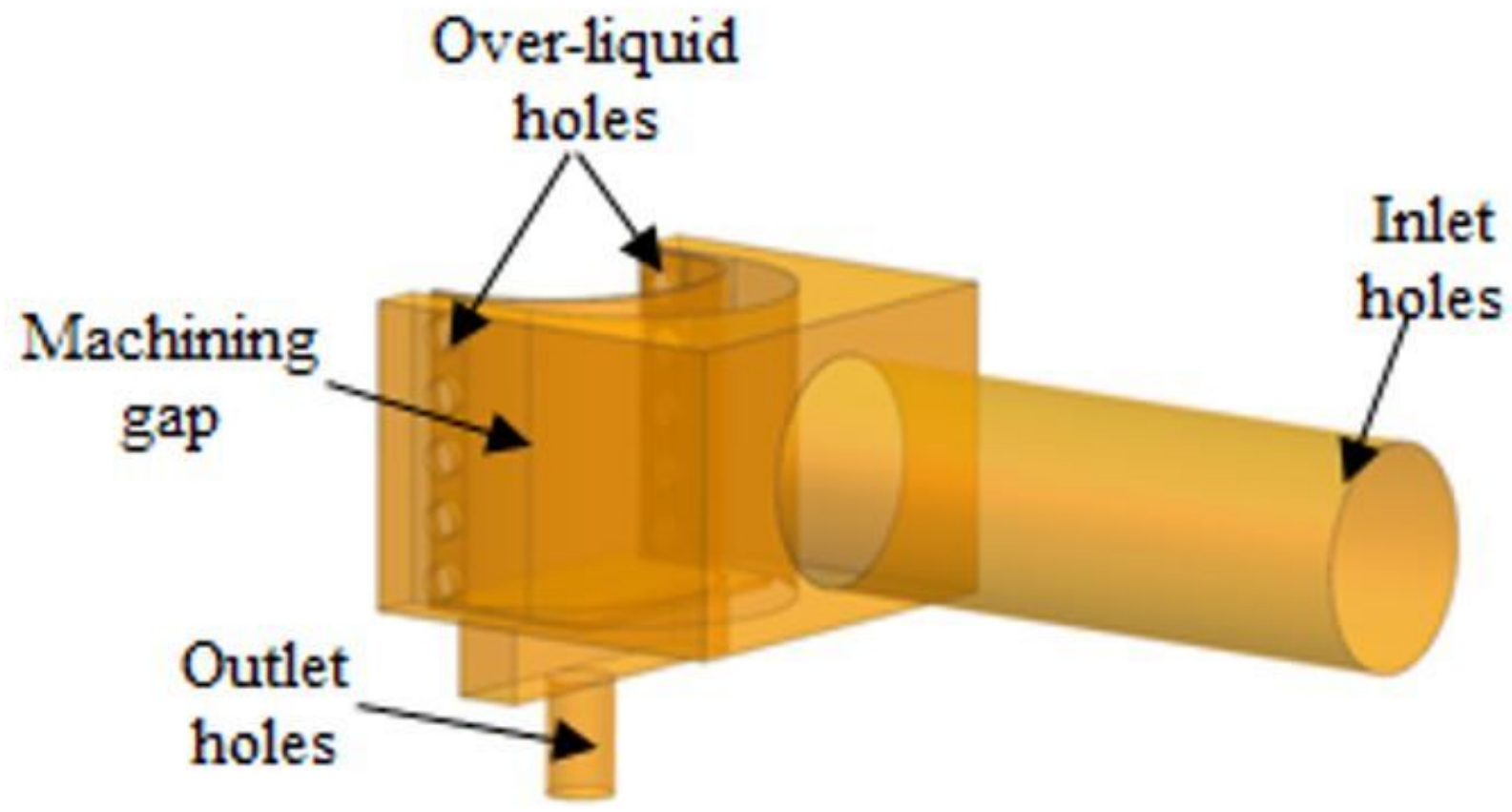

(b) Flow structure of scheme 2

Figure 5

Cathode tool flow channel structure 


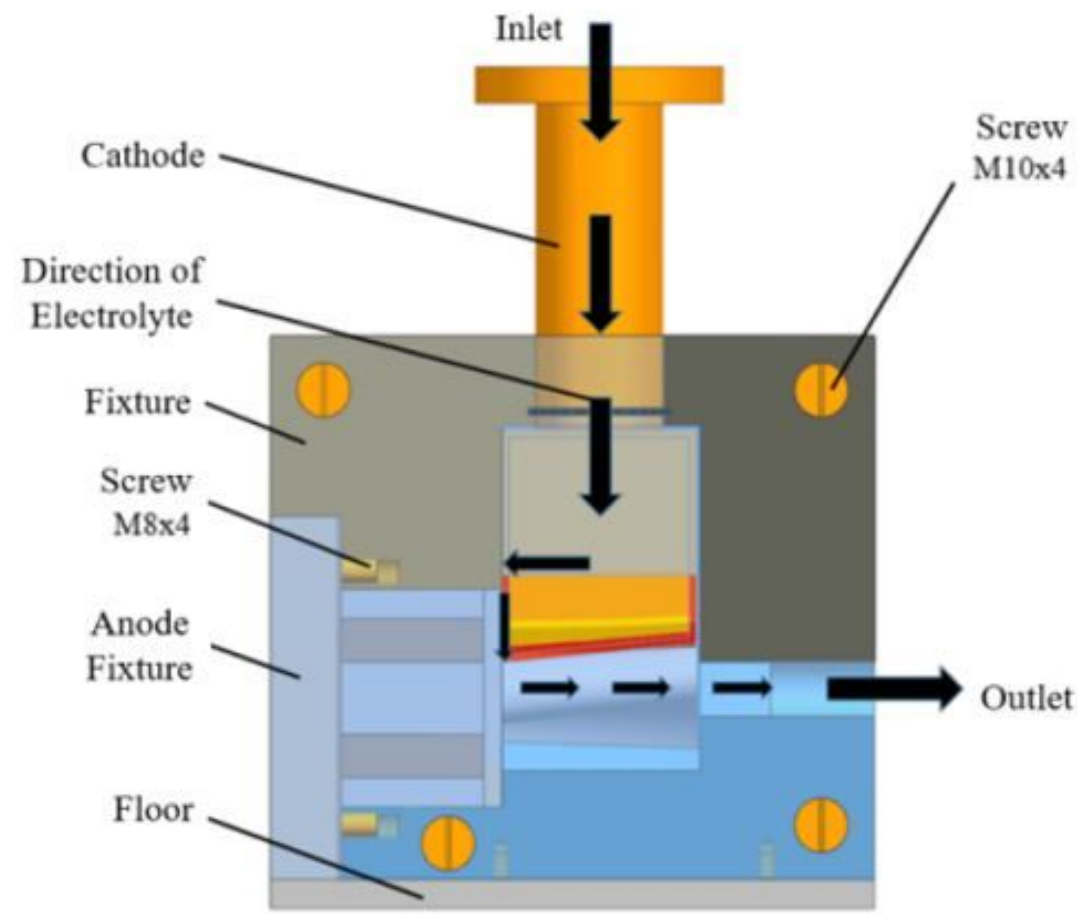

(a) Electrolyte flow mode for scheme 1

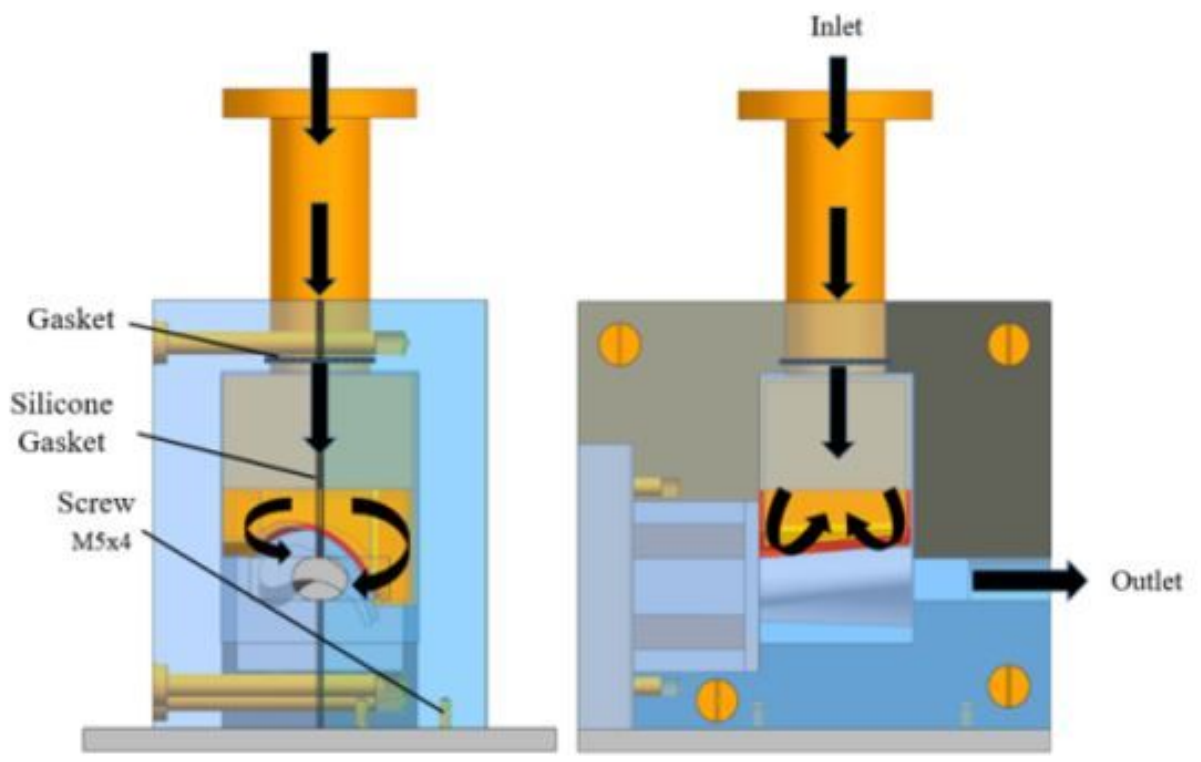

(b) Electrolyte flow mode for scheme 2

Figure 6

Fixture flow channel structure 


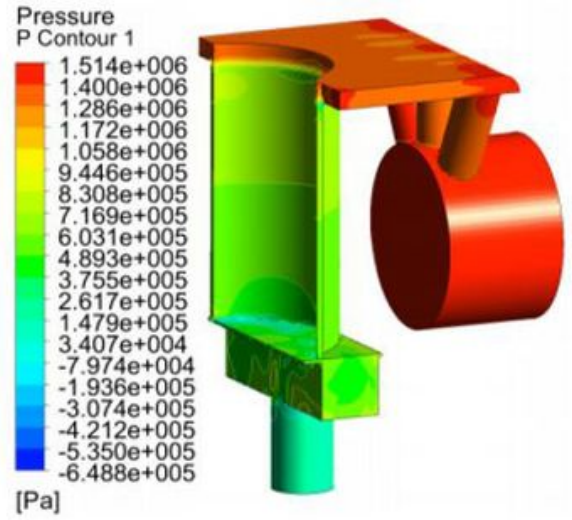

(a) Cloud diagram of electrolyte flow pressure distribution for scheme 1

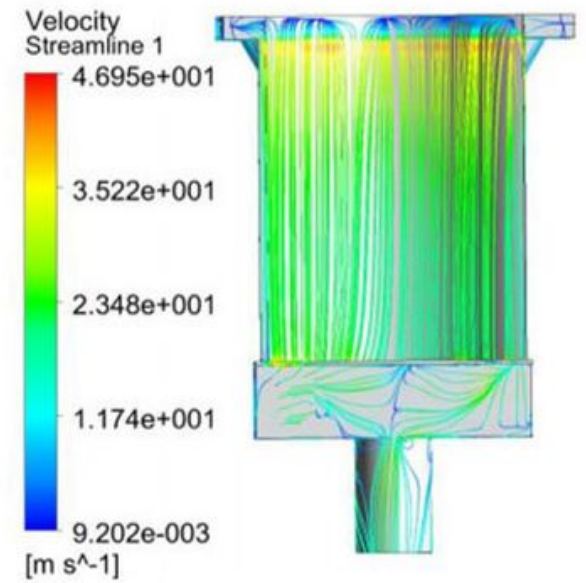

(c) Cloud diagram of electrolyte flow streamline distribution for scheme 1

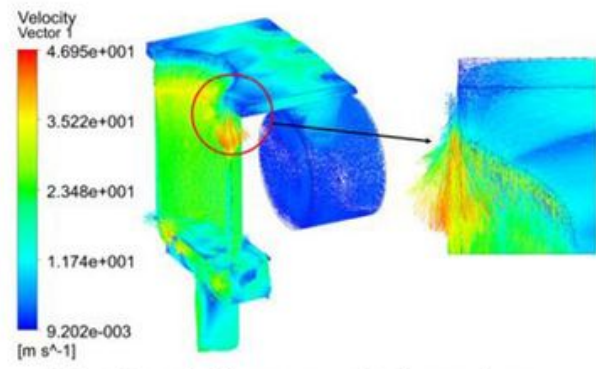

(e) Cloud diagram of electrolyte flow velocity vector distribution for scheme 1

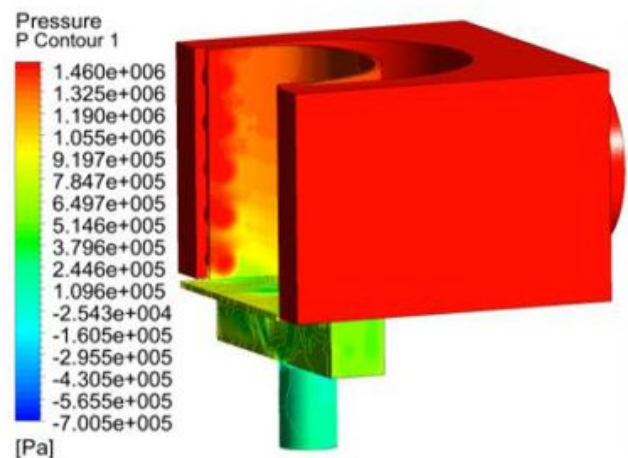

(a) Cloud diagram of electrolyte flow pressure distribution for scheme 2

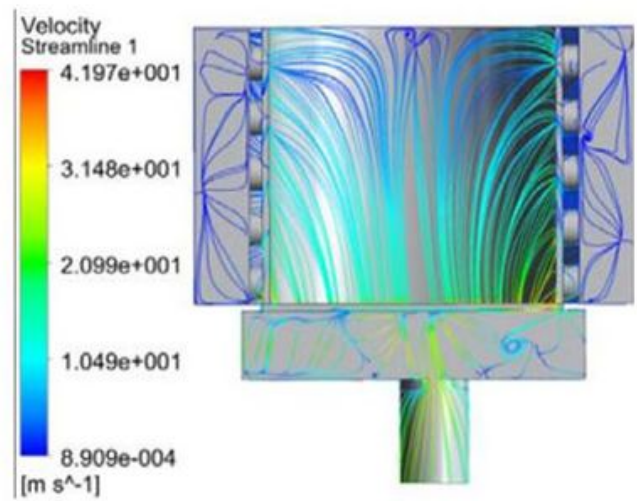

(d) Cloud diagram of electrolyte flow streamline distribution for scheme 2



(f) Cloud diagram of electrolyte flow velocity vector distribution for scheme 1

\section{Figure 7}

Cloud diagram of electrolyte flow field parameters distribution (Initial flow field) 


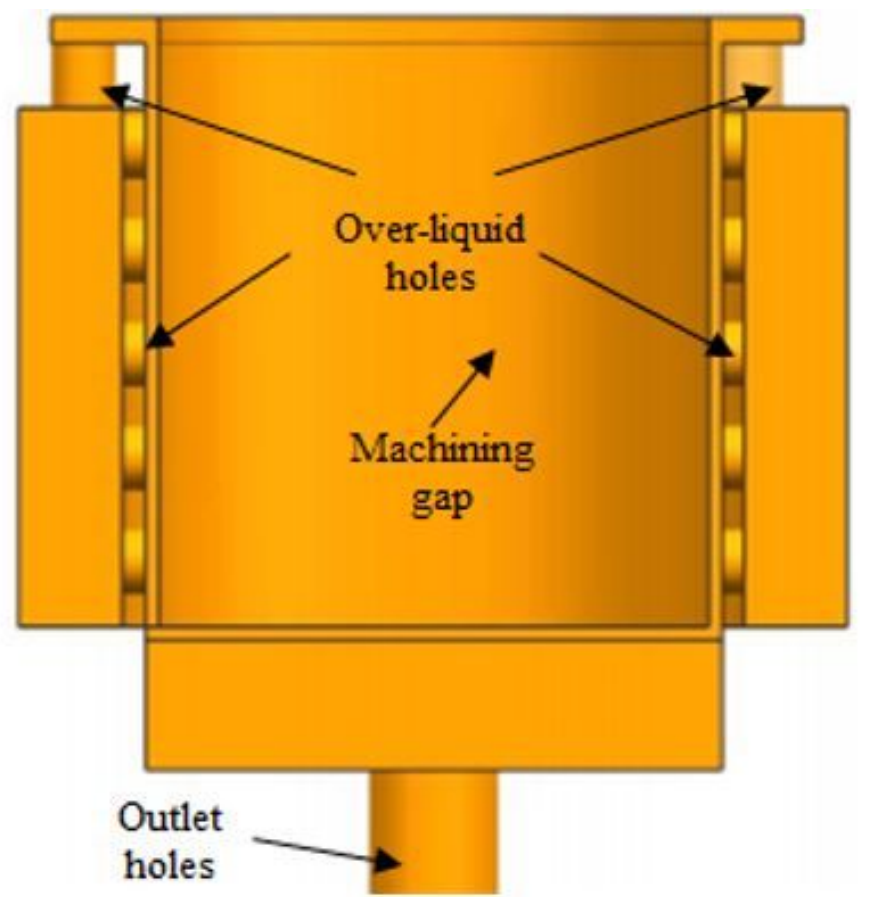

(a) Structure of optimized flow channel (front view)

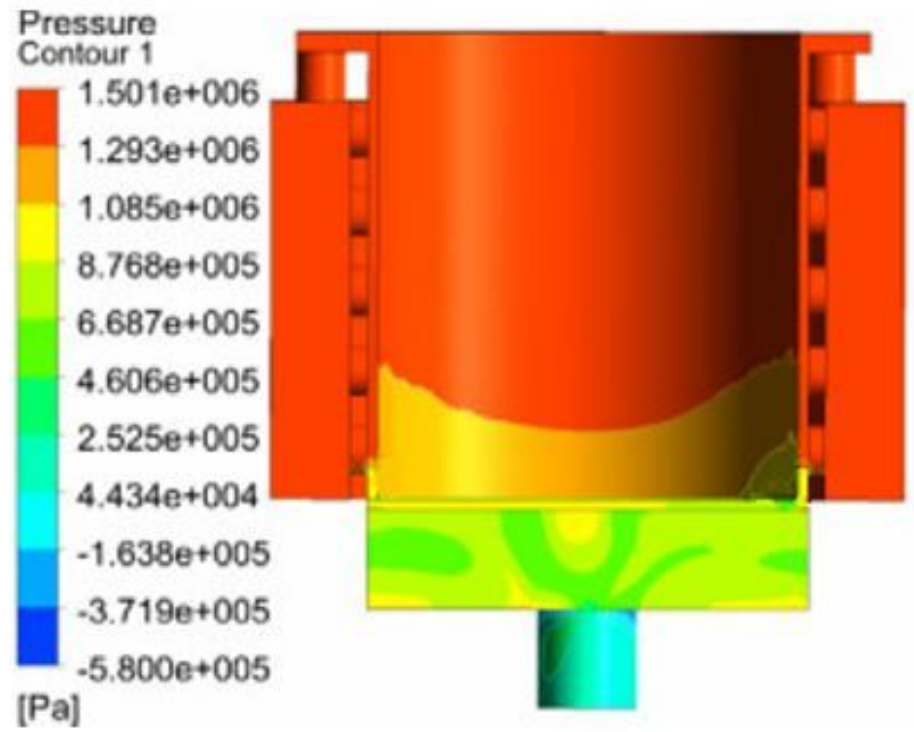

(c) Cloud diagram of electrolyte flow pressure distribution for optimized flow channel

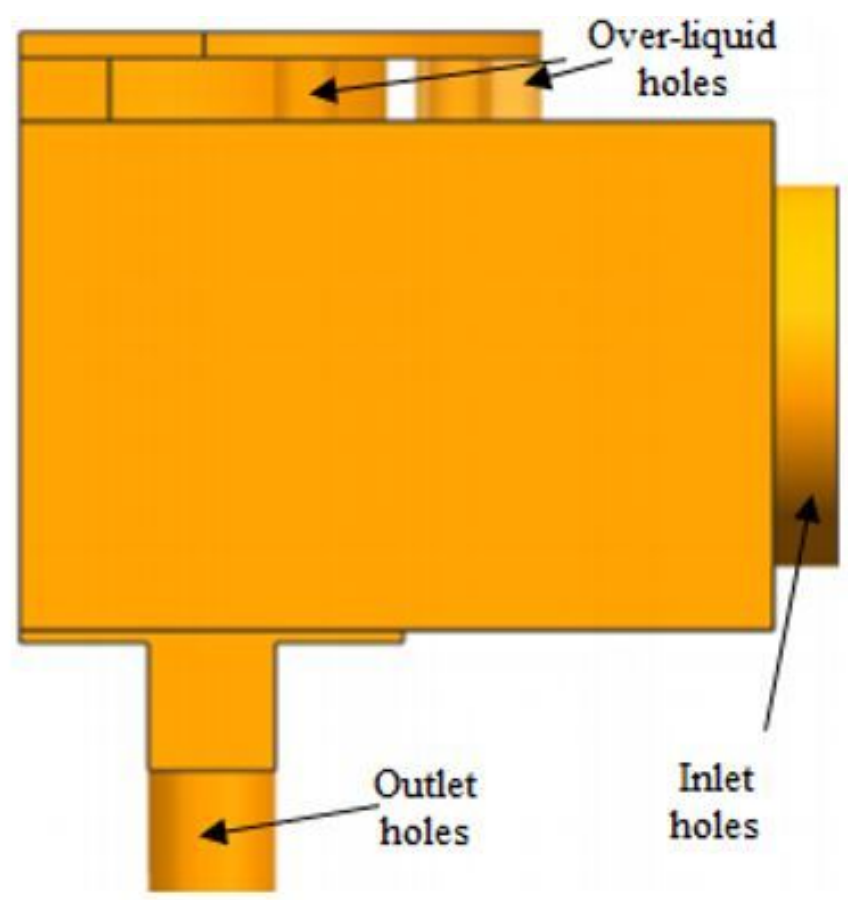

(b) Structure of optimized flow channel (side view)

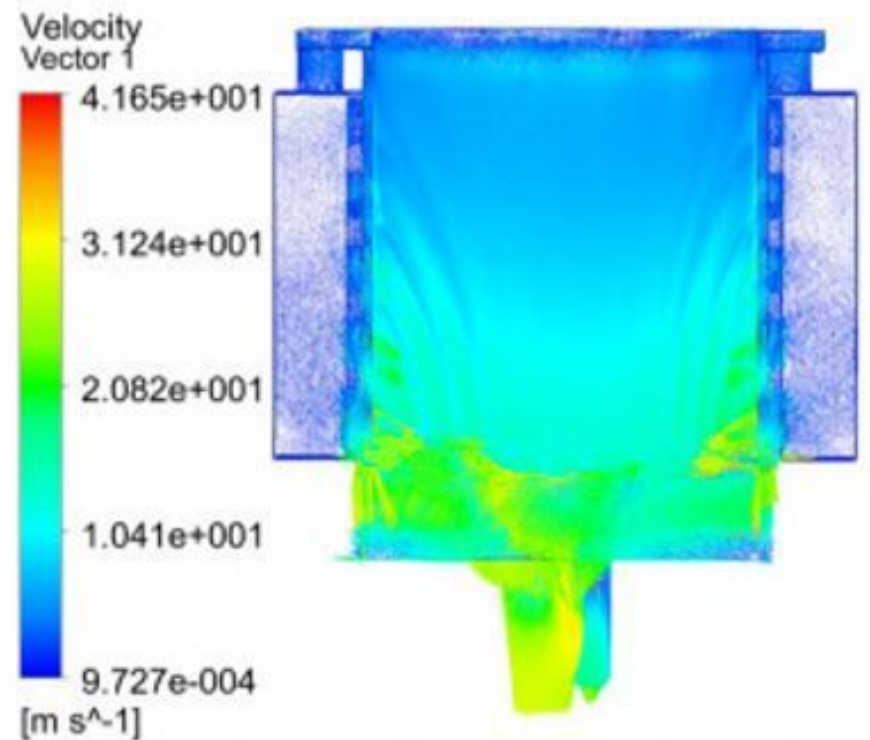

(d) Cloud diagram of electrolyte velocity distribution for optimized flow channel

Figure 8

Optimization of flow channel structure of scheme 2 


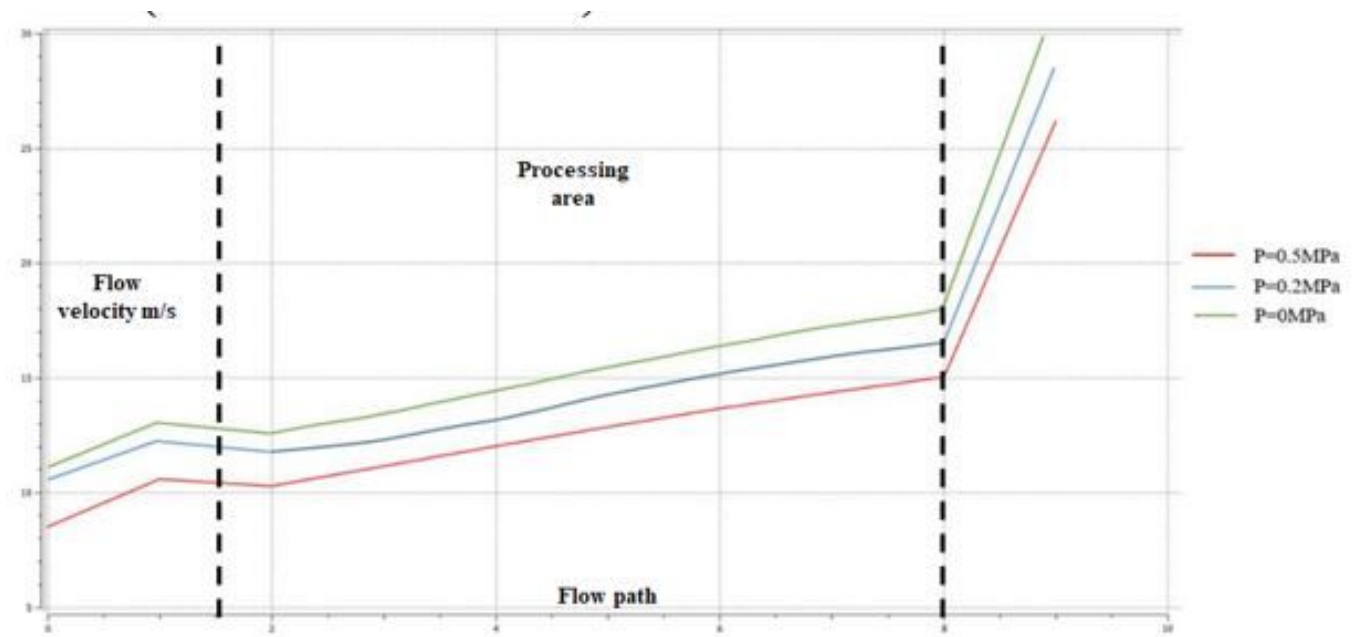

(a) Flow rate of interstitial electrolyte under different outlet pressure (Local)

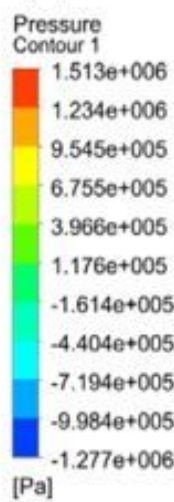

[Pa]

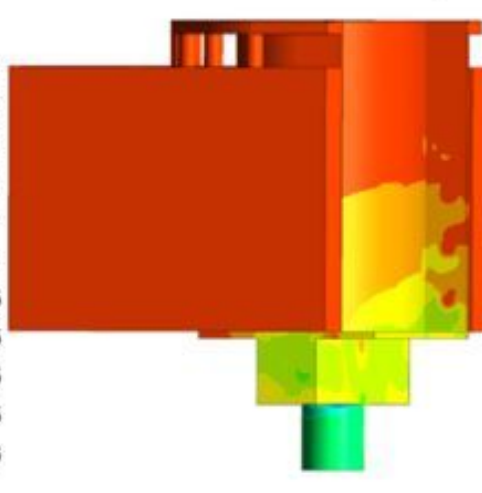

(b) $P_{\mathrm{B}}=0 \mathrm{MPa}$

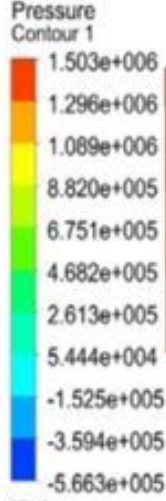

[Pa]

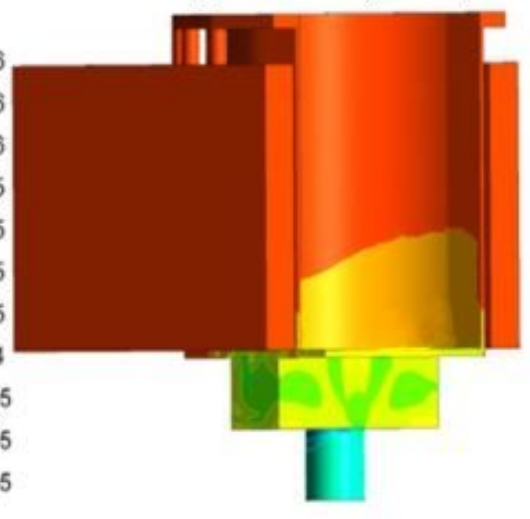

(c) $P_{\mathrm{B}}=0.2 \mathrm{MPa}$

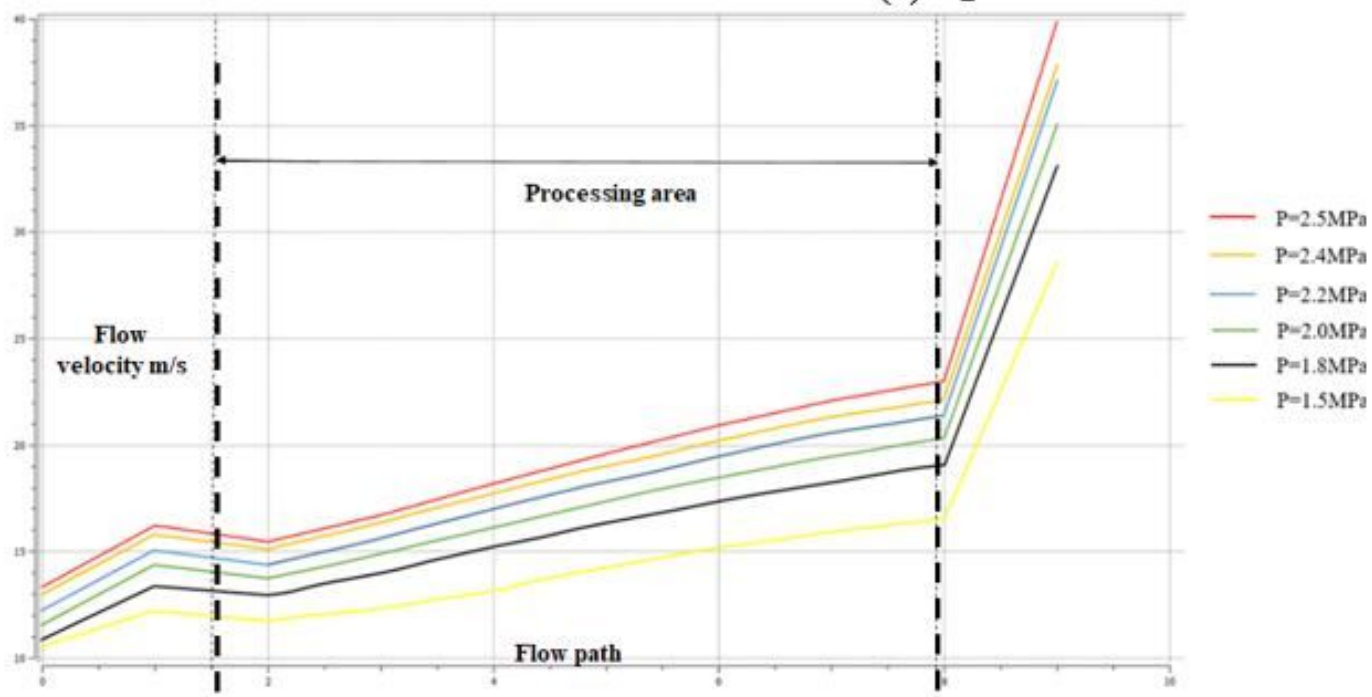

(d) Flow rate of interstitial electrolyte under different inlet pressure (Local)

\section{Figure 9}

Analysis of the relationship between different process parameters and flow field 


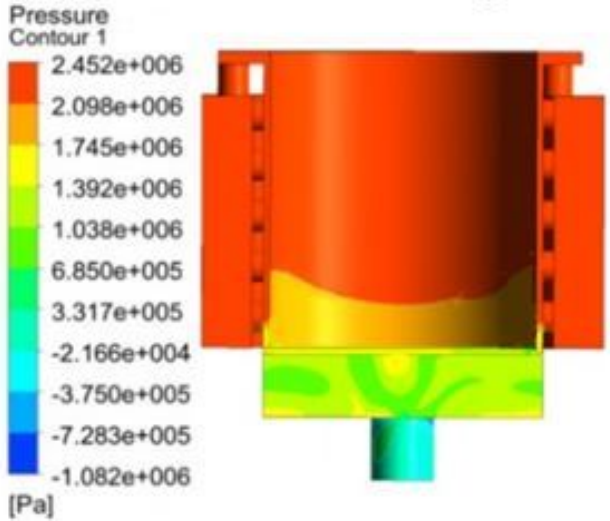

(a) Cloud diagram of electrolyte flow pressure distribution for blade back flow channel



(c) Cloud diagram of electrolyte velocity distribution for blade back flow channel

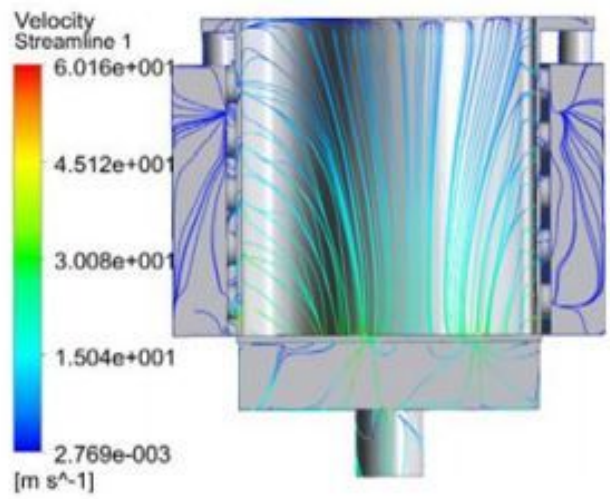

(e) Cloud diagram of electrolyte flow streamline distribution for blade basin flow channel
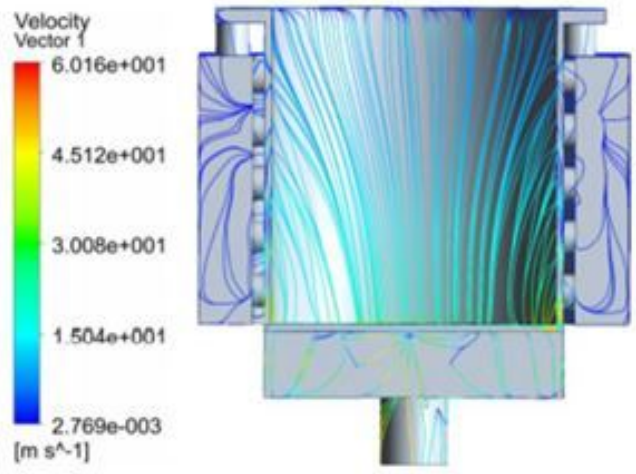

(b) Cloud diagram of electrolyte flow streamline distribution for blade back flow channel



(d) Cloud diagram of electrolyte flow pressure distribution for blade basin flow channel

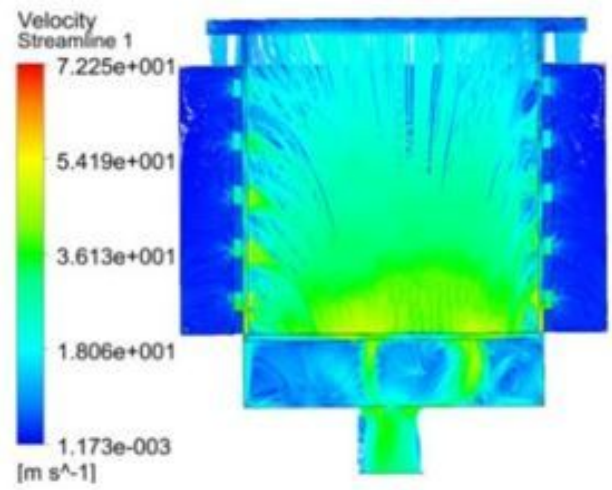

(f) Cloud diagram of electrolyte velocity distribution for blade basin flow channel

\section{Figure 10}

Analysis of optimal flow field of aero-rotor blades 


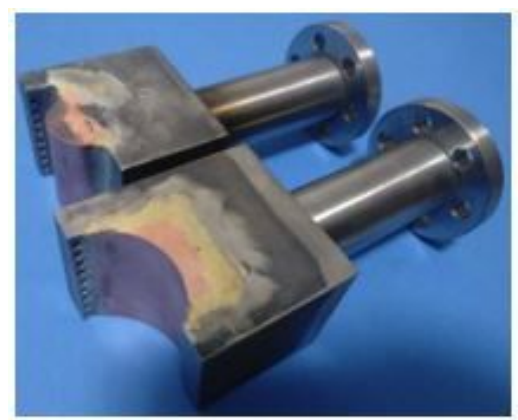

(a) Initial flow channel

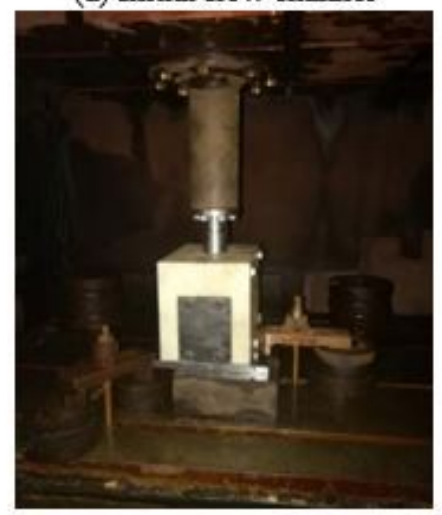

(c) Fixture

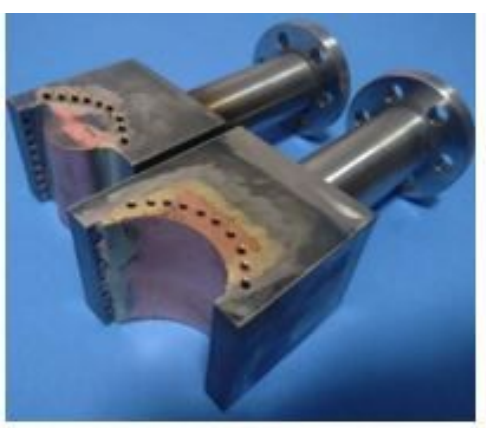

(b) Optimized flow channel



(d) Final products

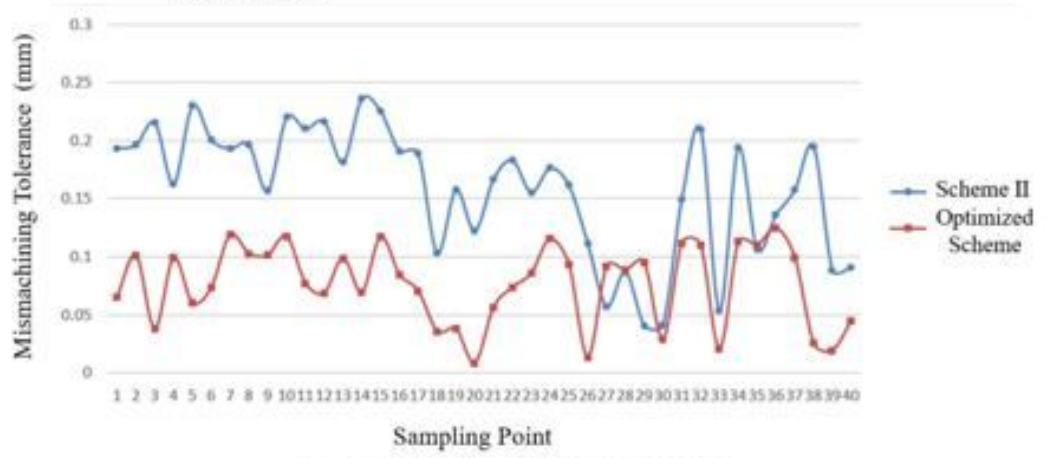

(e) Surface error of blade basin

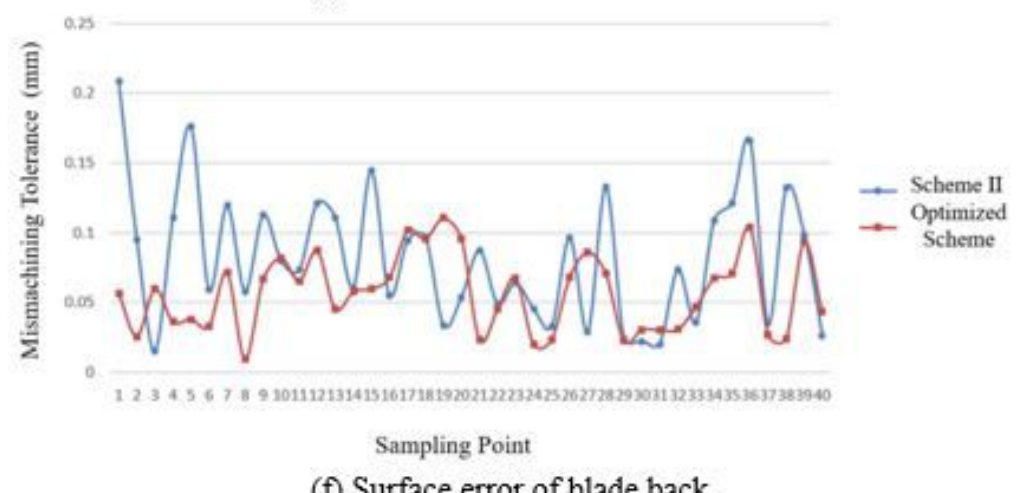

(f) Surface error of blade back

\section{Figure 11}

surface roughness of aero-rotor blade were analyzed by using three coordinate measuring instrument and roughness measuring instrument, respectively.

\section{Supplementary Files}


This is a list of supplementary files associated with this preprint. Click to download.

- Graphicalabstract.png 